\title{
FACTORS AFFECTING CORNEAL ENDOTHELIAL MORPHOLOGY
}

\author{
DISSERTATION \\ Presented in Partial Fulfillment of the Requirement for \\ the Degree Doctor of Philosophy in the Graduate \\ School of The Ohio State University
}

By

Huan Sheng, MD

$* * * * *$

The Ohio State University

2006

\begin{abstract}
Dissertation Committee:
Dr. Mark Bullimore, Advisor

Dr. Karla Zadnik

Dr. Barbara Fink
\end{abstract}

Approved by

Advisor

Vision Science Graduate Program 



\begin{abstract}
Corneal endothelial morphology is influenced by age and long term contact lens wear. The effect of refractive error, particularly high myopia has not been established. People with higher myopia are more likely to wear contact lenses and for longer, so age, contact lens wear, and degree of myopia may act independently or interact to change corneal endothelial morphology. We investigated the effects of age, race, years of contact lens wear, and degree of myopia on three key aspects of corneal endothelial morphology: endothelial cell density (ECD), coefficient of variation (polymegathism/CoV), and percentage of hexagonal cells (pleomorphism/\%Hex)
\end{abstract}

A total of 149 subjects with a broad variation in age (19 to 71 years, mean $=33.2$ years), refractive error (39.6\% had myopia over $-5.00 \mathrm{D})$, and contact lens history (13.4\% had worn lenses for $>20$ years) were examined. One third were Asian. The Konan NonCon Robo 9000 specular microscope was used to capture corneal endothelial images from one eye of each subject. The images were analyzed with the KSS-300 center method. Multiple regression analysis was used to build models of endothelial cell density, coefficient of variation, and percentage of hexagonal cells as a function of age, race, refractive error (Rx), and contact lens wear (CLyears). 
Age and race significantly affected ECD, but refractive error or years of contact lens wear did not (model: $\mathrm{ECD}=3274-12.7^{*}$ Age $+[164$ if Asian]). Years of contact lens wear, age, and their interaction significantly affected $\mathrm{CoV}$ (model: $\mathrm{CoV}=24.3+$ $0.72 *$ CLyears $+0.18 *$ Age $-0.011 *$ interaction). Years of contact lens wear, age, and degree of myopia significantly affected $\% \mathrm{Hex}$ (model: \%Hex $=70-0.29 *$ CLyears $0.21 *$ Age $+0.4 * \operatorname{Rx})$.

The three key aspects of corneal endothelial morphology are not influenced by the same factors. Endothelial cell density is significantly affected by age and race. In contrast, coefficient of variation and percentage of hexagonal cells are affected by age, years of contact lens wear and, in the case of percentage of hexagonal cells, the degree of myopia. Therefore, in studying of the influence of drugs, intraocular devices, or disease on the corneal endothelium, coefficient of variation and percentage of hexagonal cells might be more sensitive than endothelial cell density. 


\section{ACKNOWLEDGMENTS}

I would like to express my gratitude to Dr. Mark Bullimore for all his help during my Ph.D study.

I would like to thank Dr Karla Zadnik and Dr. Barbara Fink for their precious comments and suggestions on my dissertation

I am grateful to Dr. Don Mutti who has provided me with a very flexible working schedule so that I could focus on my dissertation. I also would like to thank Don for all his valuable suggestions on my Ph.D project.

Thanks also go to Emily Parker for helping me recruit subjects and analyze images.

Special acknowledgements go to Holly Omlor for reviewing and proofreading my dissertation.

Saving the most important for last, I want to thank my husband, Jinhua, for his understanding, support, and patience. 


\section{VITA}

October 26, 1969

July 1993

July 1998

June 2002
Born- ChangChun, China

MD

Norman Bethune University of Medical Science

Master of Ophthalmology

Capital University of Medical Science

MS

The Ohio State University

\section{PUBLICATION}

Huan Sheng, Carol A. Bottjer, Mark A. Bullimore: Ocular component measurement using the Zeiss IOLMaster/Optometry and Vision Science, 2004 Vol 81(1) 27-34

\section{FIELDS OF STUDY}

Major Field: Vision Science 


\section{TABLE OF CONTENTS}

Abstract

\section{Chapters:}

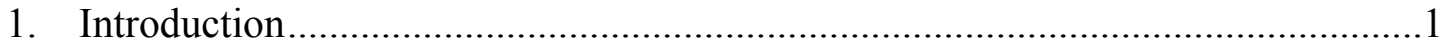

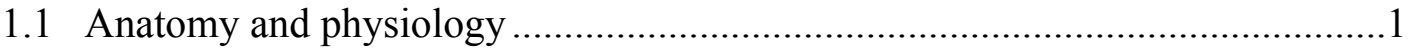

1.2 Measurement of corneal endothelial morphology ......................................5

1.3 The relationship between morphology change and functional change...............8

1.4 Functional measurement of corneal endothelium ........................................... 11

1.5 Factors affecting corneal endothelial morphology ......................................12

1.6 The role of refractive error in corneal endothelial morphology change ...........18

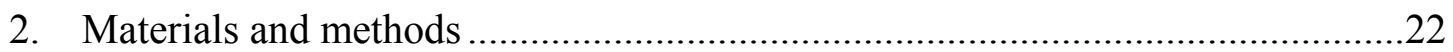

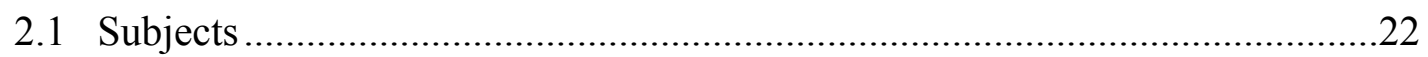

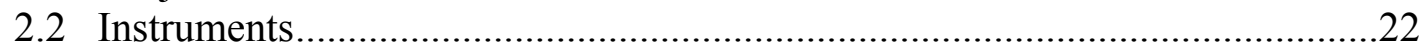

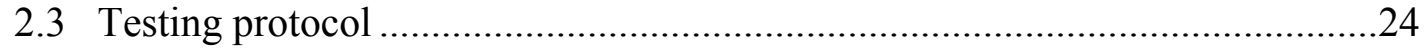

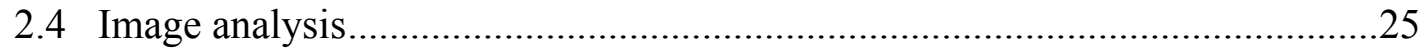

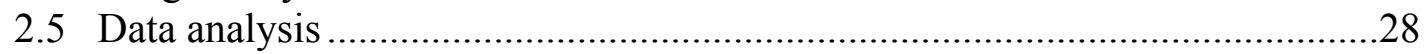

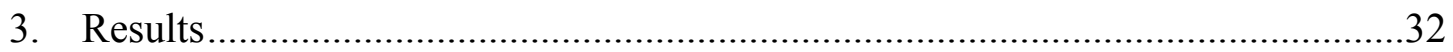

3.1 Regression model of corneal endothelial cell density..................................34

3.1.1 Scatterplots of corneal endothelial cell density ......................................34

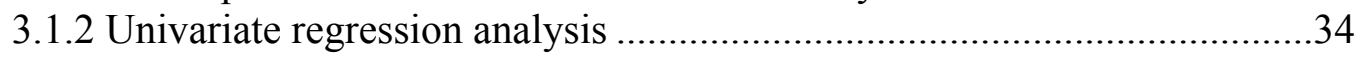

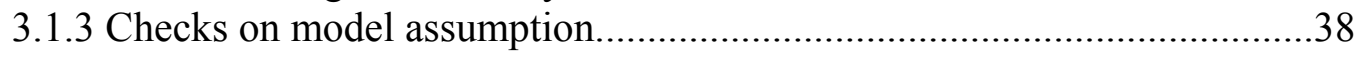

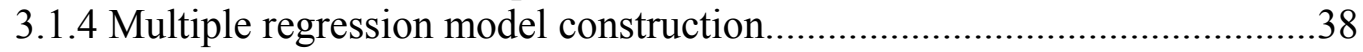

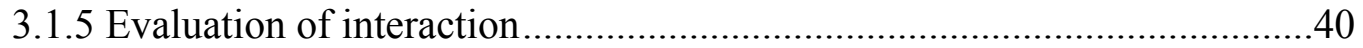

3.1.6 Model assumptions check of the final model .......................................40

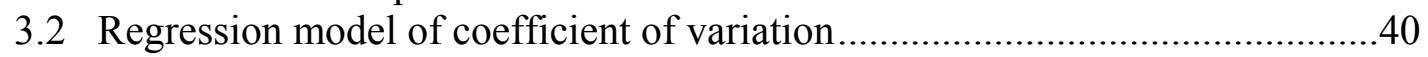

3.2.1 Scatterplots of corneal endothelial cell density .....................................40

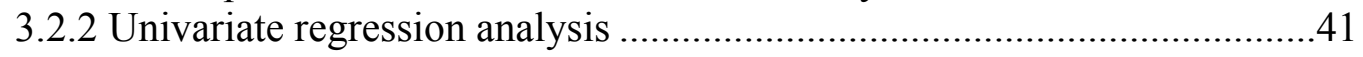


3.2.3 Checks on model assumption..................................................................4

3.2.4 Multiple regression model construction......................................................45

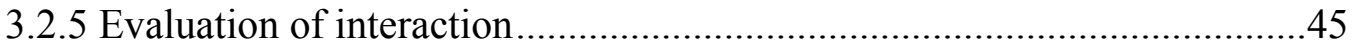

3.2.6 Model assumptions check of the final model ............................................46

3.3 Regression model of percentage of hexagonal cells ..........................................46

3.3.1 Scatterplots of corneal endothelial cell density ..........................................46

3.3.2 Univariate regression analysis ................................................................47

3.3.3 Checks on model assumption...................................................................50

3.3.4 Multiple regression model construction.....................................................50

3.3.5 Evaluation of interaction.......................................................................

3.3.6 Model assumptions check of the final model ...........................................52

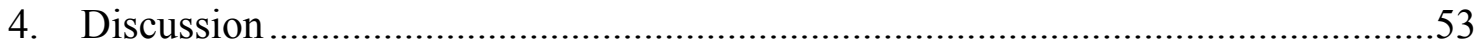

5. Evaluating the validity of confoscan 3 in corneal endothelium cell morphology

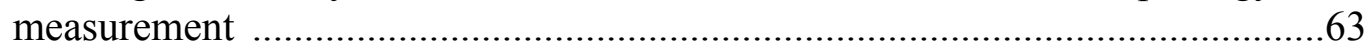

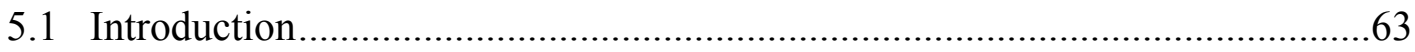

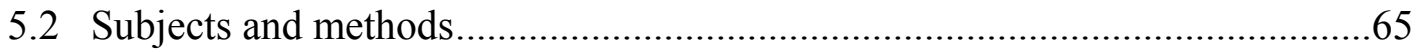

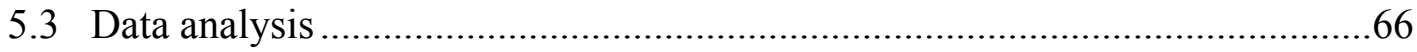

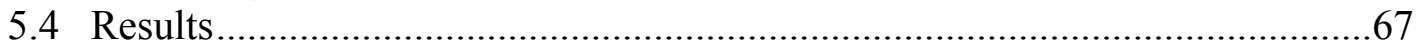

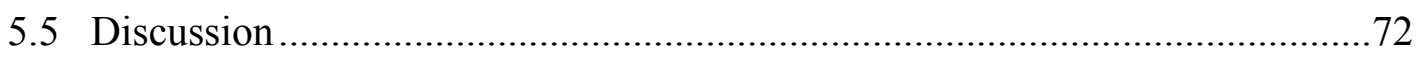

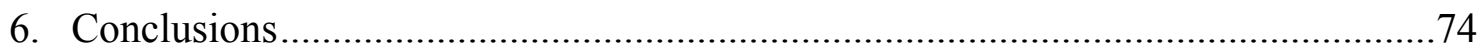

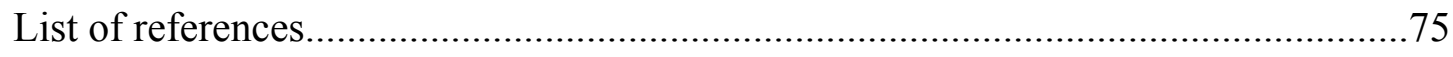




\section{LIST OF TABLES}

Table

Page

1.1 Commercially Available Corneal Endothelial Measurement Instrument .............7

1.2 Corneal Endothelial Cell Changes Caused by Contact Lens Wear ....................15

3.1 Descriptive Statistics of Age, Years of Contact Lens Wear, and Refractive

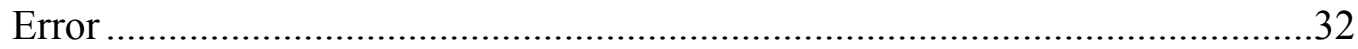

3.2 Frequencies of Age, Years of Contact Lens Wear, and Refractive Error...........33

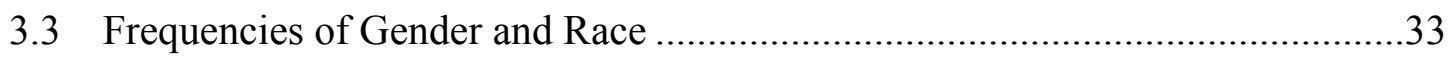

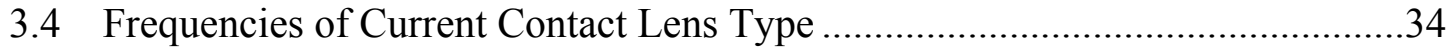

3.5 Summary of Univariate Models of Endothelial Cell Density ............................35

3.6 Checks on Model Assumption for Endothelial Cell Density ..............................38

3.7 Summary of Model Built with Age on Endothelial Cell Density ......................39

3.8 Summary of Model Built with Age and Race on Endothelial Cell Density ........39

3.9 Summary of Univariate Models of Coefficient of Variation .............................41

3.10 Checks on Model Assumption for Coefficient of Variation ..............................44

3.11 Summary of Model Built with Years of Contact Lens Wear for Coefficient

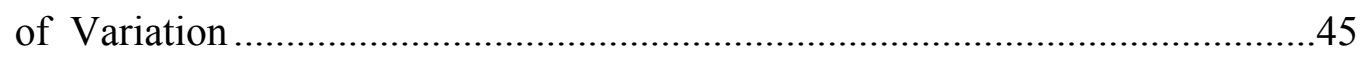

3.12 Summary of Univariate Model for Percentage of Hexagonal Cells ..................47

3.13 Checks on Model Assumption for Percentage of Hexagonal Cells ....................50

3.14 Summary on Model built with Years of Contact Lens Wear on Percentage of

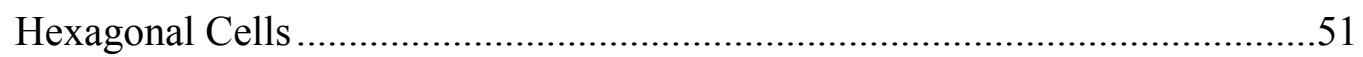

5.1 Agreement of Confoscan3 Estimates of Endothelial Cell Density with Konan KSS-300

5.2 Agreement of Confoscan3 Estimates of Percentage of Hexagonal Cells with Konan KSS-300 
5.3 Agreement of Confoscan3 Estimates of Coefficient of Variation with Konan

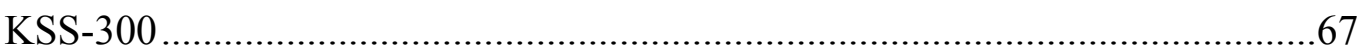




\section{LIST OF FIGURES}

$\begin{array}{lll}\text { Figure } & \text { Page }\end{array}$

3.1 Scatterplot of Endothelial Cell Density versus Age .......................................35

3.2 Scatterplot of Endothelial Cell Density versus Years of Contact Lens Wear.....36

3.3 Scatterplot of Endothelial Cell Density versus Refractive Error ........................36

3.4 Scatter plot of Endothelial Cell Density versus Race ......................................37

3.5 Scatterplot of Endothelial Cell Density versus Gender ....................................37

3.6 Scatterplot of Coefficient of Variation versus Age..........................................41

3.7 Scatterplot of Coefficient of Variation versus Years of Contact Lens Wear......42

3.8 Scatterplot of Coefficient of Variation versus Refractive Error ........................42

3.9 Scatterplot of Coefficient of Variation versus Race .......................................43

3.10 Scatterplot of Coefficient of Variation versus Gender .....................................43

3.11 Scatterplot of Percentage of Hexagonal Cells versus Age................................47

3.10 Scatterplot of Percentage of Hexagonal Cells versus Percentage of Hexagonal Cells Years of Contact Lens Wear ...............................................48

3.13 Scatterplot of Percentage of Hexagonal Cells versus Refractive Error ..............48

3.14 Scatterplot of Percentage of Hexagonal Cells versus Race ...............................49

3.15 Scatterplot of Percentage of Hexagonal Cells versus Gender ..........................49

5.1 Agreement between Confoscan3 auto and Konan in ECD measurement............69

5.2 Agreement between Confoscan3 semi-auto and Konan in ECD measurement...69

5.3 Agreement between Confoscan3 auto and Konan in Coefficient of

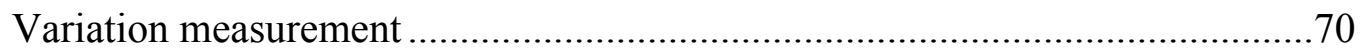

5.4 Agreement between Confoscan3 semi-auto and Konan in Coefficient of

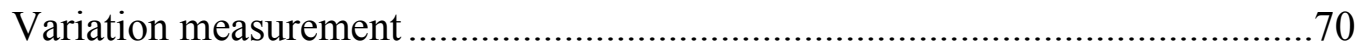

5.5 Agreement between Confoscan3 auto and Konan in \%Hex measurement...........71

5.6 Agreement between Confoscan3 semi-auto and Konan in \%Hex measurement.71 


\section{CHAPTER 1}

\section{INTRODUCTION}

\subsection{Anatomy and physiology}

The corneal endothelium is the most posterior layer of the cornea. It is a monolayer of regularly arranged polygonal squamous cells that originate from neural crest and uniformly distribute over the cornea. Corneal endothelium morphology status is usually described by three aspects:

- Endothelial cell density (ECD), which is the number of corneal endothelial cells per square millimeter.

- Coefficient of variation $(\mathrm{CoV})$, which is the mean cell area divided by standard deviation of cell area.

- Percentage of six-sided or hexagonal cells (\% Hex).

The corneal endothelial cell density varies greatly from person to person at birth. Speedwell studied the eyes of 48 infants from 6 days to 12 months old and found that the corneal endothelial density ranged from 2987 to 5624 cells $/ \mathrm{mm}^{2}$ with a mean density of 4252 cells $/ \mathrm{mm}^{2}$ (Speedwell, Novakovic et al. 1988). After birth, a large decrease in endothelial cells was found during infancy, especially in the first few months (Bahn, 
Glassman et al. 1986). The decrease in endothelial cell density decrease continues up to adolescence. Nucci studied the eyes of 240 children from 5 to 14 year old and found a mean corneal endothelial cell density of 3591 cells $/ \mathrm{mm}^{2}$ at age 5 and 2730 cells $/ \mathrm{mm}^{2}$ from age 10 to 14 (Nucci, Brancato et al. 1990). In adults, the corneal endothelial cell density decreases less rapidly with age. Hoffer et al. studied 3000 preoperative cataract patients from 40 to 90 years old and found the mean corneal endothelial cell density to be 2400 cells $/ \mathrm{mm}^{2}$ (Hoffer and Kraff 1980). The limited mitosis of the corneal endothelium cells and the increase of corneal surface may cause the rapid decrease of corneal endothelium cell density in infancy. In the first year after birth, corneal diameter increases from $10 \mathrm{~mm}$ to $11.7 \mathrm{~mm}$ (Marshall and Grindle 1978), corneal endothelial cells have to spread to cover the increased corneal area and thus cause decreased cell density count. However, for older children and adults, the limited mitosis ability of corneal endothelial cells may account more for decreased corneal endothelial cell density. Because corneal development is completed very soon after birth and the size of cornea of older children is not much different from adults, but there is still a significant reduction in corneal endothelial cell density; therefore the limited mitosis ability of the corneal endothelium may play a more important role in the normal reduction in corneal endothelial density in adults.

The anterior plasma membranes of the corneal endothelial cells are attached to Descemet's membrane by modified hemidesmosomes. There are 25 to $40 \mathrm{~nm}$ of intercullar space between adjacent endothelial cells, and the space narrows at the apical borders where junctional complexes exist. There are tight junctions, macula adherens, 
and macula occludens where cell membranes are fused, and also gap junctions where the membranes separate for about $2 \mathrm{~nm}$. Large numbers of mitochondria, Golgi apparatus, and rough and smooth endoplastic reticula are also found in the corneal endothelium (Waring, Bourne et al. 1982). In a study of human corneal endothelial cDNA library, the gene transcript of PGD2 synthase was found to be the most abundant transcript gene. In the human eye, PGD synthase has been found to be synthesized in the iris, ciliary body, and pigment epithelium cell. Existence of PGD in corneal endothelial cells suggests that there might be some similarity between corneal endothelium and iris, ciliary body and pigment epithelium (Sakai, Kinouchi et al. 2002).

The corneal endothelium plays an important role in regulating stromal hydration and maintaining the transparency of the cornea by constantly removing the fluid out of the corneal stroma. This function is executed by active metabolic pumps in the corneal endothelium. Normal corneal hydration represents a balance between the leak across the endothelium and the movement of water by the metabolic pump. At least three ion transport pumps have been identified. They are as follows: sodium-potassium pump which moves sodium ion out of the cells and depends on the Na/K ATPase; sodiumhydrogen pump which moves sodium ions into the cells; bicarbonate pump which transports bicarbonate ions from the cornea into the aqueous humor. These ion transport pumps work together to maintain the corneal transparency. When endothelial function 
fails, aqueous humor diffuses into the corneal stroma and produces corneal swelling. Therefore corneal hydration control is the most important index of corneal endothelial cell function.

Recently, it has been reported that mRNA and proteins of human epithelial mucin (MUC1), which is a mucin present in many human cells that are awash with fluid, is expressed in the human corneal endothelium. This discloses that other mechanisms, in addition to the pumps on the corneal endothelium, may be involved in maintaining the transparency of the cornea and controlling the stroma hydration (Jung, Seo et al. 2002).

In a healthy cornea, more than $60 \%$ of the corneal endothelium cells are six-sided (Doughty 1998). Using scanning electron micrographs, Doughty found that cells of rabbit corneal endothelium are six sided but not very symmetrical, therefore a hexagonal cell is probably not a very accurate description of corneal endothelium shape even though it is still widely used (Doughty, Fonn et al. 1993). The percentage of six-sided cells decreases with aging and contact lens wear (Yee, Matsuda et al. 1985). A decrease in six-sided cells and a corresponding increase in cells with more or fewer than six sides is called pleomorphism. When some corneal endothelial cells die and disappear because of aging, trauma, or other stress, such as contact lens wear, the remaining cells cannot divide fast enough to replace the dead cells. Instead, they enlarge and spread to cover the dead cells in order to maintain the intact monolayer mosaic (Waring, Bourne et al. 1982). However, not all corneal endothelial cells enlarge to the same degree; therefore, some of the cells 
became larger than others, and thus increase the variation of cell shapes and sizes. This phenomenon is described by the coefficient of variation $(\mathrm{CoV})$, which is calculated as the standard deviation of mean cell area divided by the mean cell area. An increase in coefficient of variation is called polymegethism. Even though the size of cells is different in cross sectional view, cells exhibiting polymegethism may not be different in terms of cell volume. Transmission electron microscopy study of contact lens induced corneal endothelial polymegethism showed that there was oblique reorientation of the lateral endothelial walls; thus it is possible that a corneal endothelial cell with larger anterior surface area may have smaller posterior surface area, and vice versa (Bergmanson 1992). Therefore, what polymegethism represents is the cross-sectional cell shape change, not the cell volume change.

The underlying mechanism which causes polymegethism and pleomorphism is possibly related to changes in endothelial cytoskeletal F-actin. Cytoskeletal F-actin plays an important role in maintainging the cell shape. Stress such as contact lens wear may affect the cysoskeletal F-actin and then cause the corneal endothelial cell shape change (Kim, Geroski et al. 1992; Azar, Holdbrook et al. 2001).

\subsection{Measurement of Corneal endothelial Morphology}

Corneal endothelial morphology can be measured with different instruments, including contact specular microscopes, non-contact specular microscopes, and confocal microscopes. Early versions of specular microscopes were contact types that needed the 
water immersion objective lens and dipping cone to lie directly on the corneal surface to obtain higher magnification and better resolution. Therefore, patients' tolerance was a problem when taking a measurement. With improvements in technology, modern versions of the wide-field specular microscopes are non-contact; they are more patient friendly and can achieve equally high magnification. Wide-field specular microscope has been widely used in studies of corneal endothelial cell changes after contact lens wear, cataract surgery, or other corneal or intraocular surgery, and eye disease (Jones, Azar et al. 1998; Smith, Khoury et al. 2000; Azar, Holdbrook et al. 2001; Lee, Park et al. 2001; Edelhauser, Sanders et al. 2004; Odenthal, Gan et al. 2005; Wirbelauer, Wollensak et al. 2005). However, there are still some limitations in using specular microscopy to capture corneal endothelial images: The corneal endothelial images of patients with Fuchs' dystrophy have many dark area where no cells could be recognized on the images taken by specular microscopy, however, confocal microscopy can overcome this problem and identify the cells (Hara, Morishige et al. 2003).

In confocal microscopy measurement of the cornea, light is sent from an illumination source and then passes through a slit and is focused on a spot within the cornea by an objective lens. Light reflected back from the cornea is filtered by another slit which blocks the out-of-focus light. A detector then receive the focused light. Because of this optical design, the image taken by confocal microscopy has a superior resolution than 
specular microscopy. However, confocal microscopes measurement of the corneal endothelial cell requires contact between the instrument and the cornea; therefore, topical anesthesia is required.

There are also different image analysis methods, including manual photo digitized, manual, semi automatic, automatic, or manual digital. Information about the corneal endothelial cell density, cell size (area), shape, and variation of cell size can be gathered after corneal endothelial image capture and analysis. Table 1.1 is a summary of the commercially available specular microscopes and their image analysis methods.

\begin{tabular}{|l|l|l|}
\hline Instrument & Keeler-Konan: SP - 580 & Analysis \\
\hline \multirow{2}{*}{$\begin{array}{l}\text { Sontact } \\
\text { specular } \\
\text { microscope }\end{array}$} & HAI Labs: HAI CL - 1000 XYZ & Manual photo digitized \\
\cline { 2 - 3 } $\begin{array}{l}\text { Non - } \\
\text { contact } \\
\text { specular } \\
\text { microscope }\end{array}$ & TOMEY: EM - 1000 & Automatic \\
\cline { 2 - 3 } & Bio Optics: LMS - 1200 & Automatic with manual \\
\cline { 2 - 3 } $\begin{array}{l}\text { Confocal } \\
\text { microscope }\end{array}$ & Konan: Robo Pachy SP - 9000 & Automatic limited \\
\cline { 2 - 3 } & Konan: Robo CA SP -8800 & Manual digital \\
\cline { 2 - 3 } & ConfoScan3 (Nidek Technologies) & $\begin{array}{l}\text { Manual, semi-automatic, } \\
\text { automatic }\end{array}$ \\
\hline
\end{tabular}

Table 1.1 Commercially Available Corneal Endothelial Measurement Instrument

Corneal endothelial measurement instruments and image analysis methods have been widely evaluated. The specular microscope has been shown to be reliable and reproducible with appropriate calibration of the instrument (Benetz, Diaconu et al. 1999; Modis, Langenbucher et al. 2002; van Schaick, van Dooren et al. 2005). The Konan Noncon Robo and KSS-300 software has 2\% precision of corneal endothelial density 
measurement in a single clinical site, single photographer, and a single reader study; for multicenter study, precision varies from $8 \%$ to $10 \%$ with a single reader (Edlhauser, personal communication). A good specular microscope image should have distinct cells that can be grouped in a uniform area, and can identify at least 100 cells (Edlhauser, personal communication). A reliable corneal endothelial cell count result is best achieved with a higher number of counted cells in a image (Cho and Cheung 2000). Lower numbers of counted cells may cause less reliable results (Nichols, Kosunick et al. 2003). The coefficient of variation for polymegethous corneal endothelium is less reliable than normal corneal endothelium (Doughty, Fonn et al. 1993).

In an "Ophthalmic Procedure Assessment" of corneal endothelial photography by the American Academy of Ophthalmology (1997), it was concluded that "Corneal endothelial photography has been shown to be a safe, reliable, and effective means to ascertain corneal endothelial cell density $\left(\mathrm{cell} / \mathrm{mm}^{2}\right)$ and to provide information regarding cell morphometry (functional status).”

\subsection{The Relationship Between Morphological Change and Functional Change}

Past studies have shown that corneal endothelial morphology is the best indicator of corneal endothelial stress or instability (Rao, Aquavella et al. 1984; Schultz, Matsuda et al. 1984; MacRae, Matsuda et al. 1994). Endothelial morphology has been demonstrated to be the most sensitive measure of corneal endothelial stability in pseudophakic bullous keratopathy, diabetes, and contact lens wearing. Corneal endothelial morphology changes are the first indicators of endothelial stress. However, not all three aspects of corneal 
endothelial morphology change respond to stress in the same way, because there are studies that found percentage of hexagonal cells and coefficient of variation changes but without endothelial cell density change (Rao, Aquavella et al. 1984).

Functional changes often come with morphological changes in the human body. Therefore, it is possible that when corneal endothelial cell morphological abnormalities (endothelial cell density decrease, polymegethism, and pleomorphism) can be observed, corneal functional abnormalities (corneal swelling) can be measured too. Furthermore, a certain relationship could exist between the corneal endothelial morphology and function, i.e. high functional level corresponds to high corneal endothelial cell density and low functional level corresponds to low corneal endothelial cell density. If this relationship could be found, the level of corneal endothelial cell density, polymegethism, and pleomorphism, which can be directly gathered from the corneal endothelial measurement, would provide much more information about the functional level of the corneal endothelium for the clinical workers, especially when the patient is older and ocular surgery is being considered.

For patients who have endothelial morphological abnormalities that are caused by long-term contact lens wear, diabetes, or corneal endothelial disorders, the underlying corneal function abnormalities may already exist. But because remaining corneal endothelium or the endothelium reserve can still function to maintain the transparency of the cornea, no regular clinical examination such as slit lamp examination or visual acuity 
test could find any functional abnormality of the cornea. Potential corneal decompensation exists when triggered by stresses such as cataract surgery or other ocular surgery. Therefore other corneal endothelial function evaluation methods are necessary. Patients who have low corneal endothelial cell density are distinct on some aspects:

- Diabetes and high myopia patients have a higher probability of developing cataracts.

- Cataract surgery was found to be associated with high myopia (Younan, Mitchell et al. 2002) and diabetes.

- Some myopia subjects who are former contact lens wearers may choose other methods of vision correction such as Implantable Contact Lens (ICL) or intrastromal corneal ring segments (INTACS).

Cataract surgery may cause corneal endothelial cell loss. Even though the phacoemulsification procedure has been improved greatly and new hyaluronate viscoelastic materials have been produced, endothelial cell damage is still unavoidable in many cases. Bourne et al. reported a study of 433 patients and found there was an average of $10 \%$ reduction in corneal endothelial cell count by 1 year after both phacoemulsification and extracapsular cataract surgery, while no such change in hexagonality or in the coefficient of variation were found (Bourne, Minassian et al. 2004). Another study which was performed by Bourne on endothelial cell loss ten years after intraocular lens implantation on 67 eyes also found that the rate of corneal endothelial cell loss from 1 to 10 years after the cataract surgery was $2.5 \%$ per year. 
Matsuda et al found that the frequency of hexagonal cells decreases from $68 \%$ preoperatively to $52 \%$ at four weeks after the cataract surgery and to $64 \%$ at 24 weeks after the surgery (Matsuda, Suda et al. 1984). Olsen also found that corneas after cataract extraction have a lower endothelial cell count and higher frequency of non hexagonal cells (Olsen 1979). Menezo et al reported that the iris fixated phakic IOL could cause progressive endothelial cell loss as high as $4.6 \%$ from 1 year to 2 years and $2.6 \%$ from 2 years to 3 years (Menezo, Cisneros et al. 1998). Edelhauser et al reported that the endothelial cell loss rate after the Implantable Contact Lens (ICL) surgery was $0.6 \%$ per year over the first 3 years and was $0.1 \%$ between years 3 and 4 . Azar et al assessed the corneal endothelium after INTAC implantation and found slight central cell loss (28 cells $/ \mathrm{mm}^{2}$ ) at 24 months after the surgery (Azar, Holdbrook et al. 2001). Therefore, assessing the corneal endothelium function in addition to the clinical examination on the patients who have endothelial morphological abnormalities will provide more information about their corneal reserve and the ability of the cornea to withstand further management such as IOL surgery, ICL surgery, or INTAC implantation. Some cases of postoperative corneal decompensation may be avoided if preoperative corneal endothelial cell function is known.

\subsection{Functional Measurement of Corneal Endothelium}

O'Neal and Polse have shown that the in vivo corneal endothelial cell hydration control function can be evaluated by inducing corneal swelling using hypoxic stress and then monitoring the subsequent recovery of corneal thickness (O'Neal and Polse 1985). 
Corneal swelling can be induced using a thick hydrogel contact lens with the eye either open or closed (patched), or by using nitrogen gas which is supplied by a goggle to form a hypoxic environment in front of the eye. After the corneal swelling has been induced, the hypoxic stress (contact lens or nitrogen gas) is taken away and the cornea edema recovery rate is evaluated with continuous corneal thickness measurements. The deswelling rate (D) can be expressed as the percent recovery per hour (PRPH). Saini et al. further evaluated this method of in vivo assessment of corneal endothelial cell function and proved that this is a valid method (Saini, Mittal et al. 1998). This method has been used in assessing changes in corneal endothelial function with age (Polse, Brand et al. 1989), Fuchs' dystrophy (Mandell, Polse et al. 1989), diabetes mellitus (Saini and Mittal 1996), cataract surgery (Saini and Mittal 1996), and keratoplasty (Saini, Mittal et al. 1998).

\subsection{Factors affecting Corneal Endothelial Morphology}

Polymegethism and pleomorphism were first observed on corneas of contact lens wearers. In addition to contact lens wear, some other factors have also been studied and found related with corneal endothelial morphology changes. Below is a summary of the factors that have been proved to influence the corneal endothelial morphology:

\subsubsection{Contact lens wear.}

PMMA lens wear or soft lens wear (Stocker and Schoessler 1985), (Holden, Sweeney et al. 1985), (MacRae, Matsuda et al. 1985; Mac Rae, Matsuda et al. 1986; MacRae, 
Matsuda et al. 1994), (Bourne, Nelson et al. 1994), (Setala, Vasara et al. 1998), (Bourne, Holtan et al. 1999; Lee, Park et al. 2001) have been shown to cause endothelial cell density decrease, ploymegethasm, and pleomorphism. Table 1.2 is the summary of previous studies about corneal endothelial change associated with contact lens wear.

In most studies of corneal endothelial changes induced by contact lens wear, endothelial cell density decrease was not found while polymegethism or pleomorphosim were observed (Holden, Sweeney et al. 1985; MacRae, Matsuda et al. 1985; Mac Rae, Matsuda et al. 1986). On the contrary, relatively recent studies (MacRae, Matsuda et al. 1994; Setala, Vasara et al. 1998; Bourne, Holtan et al. 1999; Lee, Park et al. 2001) found that there is endothelial cell density decrease in addition to polymegethism and pleomorphism in long term contact lens wearers. A closer look at data from these studies reveals that the difference in the results of these studies could be caused by several factors:

- The sample size: studies that found endothelial cell density changes have a relatively bigger sample size than the studies that did not find endothelial cell density changes.

- Experimental instruments and image analysis methods: earlier studies which did not find endothelial cell density decreases mostly used manual cell count while relatively recent studies which found endothelial cell density decreases mostly used semi-automatic analysis. 
- Years of contact lens wear: subjects in later studies in general have a longer soft lens wear history than subjects in the earlier studies.

- Type of contact lens: subjects in the studies of contact lens induced corneal morphology change follow contact lens development, from PMMA at the very beginning, to RGP lenses, to soft lenses with low oxygen transmission, to low water content and then soft lenses with high oxygen transmission and high water content, and disposable soft lenses. Differences in contact lens type may be another factor that lead to the different results. 


\begin{tabular}{|c|c|c|c|c|c|c|c|}
\hline \multirow[t]{8}{*}{ Study } & \begin{tabular}{|l|} 
Des \\
ign
\end{tabular} & Cause & $\mathrm{N}$ & Age & ECD & CoV Increase & $\%$ Hex (\%) Decrease \\
\hline & C-S & $\begin{array}{l}\text { Soft contact lens } \\
\text { wear for } 62 \pm 29 \\
\text { month }\end{array}$ & 27 & $29 \pm 8$ & Not significant & $22.0 \%$ & N/A \\
\hline & C-S & $\begin{array}{l}\text { PMMA contact } \\
\text { lens wear for } 7- \\
15 \text { yrs }\end{array}$ & 15 & $21-52$ & Not significant & $\begin{array}{l}81.6 \% /(.445 \text { vs. } \\
.245)\end{array}$ & $\mathrm{N} / \mathrm{A}$ \\
\hline & C-S & $\begin{array}{l}\text { PMMA contact } \\
\text { lens wear for more } \\
\text { than } 10 \mathrm{yrs}\end{array}$ & 12 & $28.9 \pm 1.6$ & Not significant & $\begin{array}{l}39.1 \% /(.373 \text { vs. } \\
.268)\end{array}$ & $\begin{array}{l}16.7 \% /(52.4 \% \text { vs. } \\
69.1 \%)\end{array}$ \\
\hline & \multirow[t]{4}{*}{ C-S } & $\begin{array}{l}\text { Soft lens wear } 6.3 \\
\pm .76 \mathrm{yr}\end{array}$ & 20 & $28.0 \pm 1.4$ & Not significant & $\begin{array}{l}43 \% /(.358 \text { vs. } \\
.248)\end{array}$ & $\begin{array}{l}12.7 \% /(50 \% \text { vs. } \\
62.7 \%)\end{array}$ \\
\hline & & $\begin{array}{l}\text { PMMA } 14.9 \pm .51 \\
\text { yr }\end{array}$ & 12 & $28.8 \pm 1.0$ & Not significant & $\begin{array}{l}38 \% /(.364 \mathrm{vs} . \\
.263)\end{array}$ & $\begin{array}{l}16.7 \% /(52.4 \% \text { vs } \\
69.1 \%)\end{array}$ \\
\hline & & $\begin{array}{l}\text { PMMA } 22.9 \pm .57 \\
\mathrm{yr}\end{array}$ & 17 & $39.9 \pm 1.2$ & Not significant & $\begin{array}{l}67 \% /(.448 \text { vs. } \\
.267)\end{array}$ & $\begin{array}{l}19.3 \% /(46.9 \% \text { vs. } \\
66.2 \%)\end{array}$ \\
\hline & & $\begin{array}{l}\text { Former PMMA } \\
\text { user } 9.7 \pm 1.7 \mathrm{yr}\end{array}$ & 15 & $33.0 \pm 1.26$ & Not significant & $\begin{array}{l}18 \% /(.311 \text { vs. } \\
.263)\end{array}$ & $8.7 \%$ / (56.9 vs. 65.6$)$ \\
\hline $\begin{array}{l}\text { MacRae et } \\
\text { al. (1994) }\end{array}$ & C-S & $\begin{array}{l}\text { PMMA } 26.8 \pm .3 \\
\mathrm{yr}\end{array}$ & 81 & $46.6 \pm .78$ & $\begin{array}{l}\text { Increase in the number of } \\
\text { subjects with } E C D<2000\end{array}$ & $183 \% /(.68$ vs. .24) & $\begin{array}{l}137.9 \% /(29 \% \text { vs. } \\
69 \%)\end{array}$ \\
\hline $\begin{array}{l}\text { Setala et al. } \\
(1998)\end{array}$ & $\mathrm{C}-\mathrm{S}$ & $\begin{array}{l}\text { Soft and PMMA } \\
16.9 \mathrm{yr}\end{array}$ & 101 & 39.4 & Decrease by 94 cells $/ \mathrm{mm} 2$ & $\begin{array}{l}40.9 \% /(.31 \text { vs. } \\
.22)\end{array}$ & $\mathrm{N} / \mathrm{A}$ \\
\hline $\begin{array}{l}\text { Bourne et } \\
\text { al (1999) }\end{array}$ & $\mathrm{P}$ & $\begin{array}{l}\text { Fluorocarbon lens } \\
\text { wear }\end{array}$ & 51 & $18-80$ & $\begin{array}{l}\text { Decrease by } 8.6 \% \text { vs. } \\
0.6 \% \text { in normal eye }\end{array}$ & $\begin{array}{l}19.2 \% /(.31 \text { vs. } \\
.26)\end{array}$ & $\begin{array}{l}8.1 \% /(60.8 \% \text { vs. } \\
65.7)\end{array}$ \\
\hline \multirow[t]{2}{*}{$\begin{array}{l}\text { Lee et al. } \\
(2001)\end{array}$} & \multirow[t]{3}{*}{$\mathrm{C}-\mathrm{S}$} & Soft lens $<5 y$ & 30 & $26.4 \pm 6.3$ & Not significant & $\begin{array}{l}15.4 \% /(.30 \mathrm{vs} . \\
.26)\end{array}$ & $\begin{array}{l}8.4 \% /(76.5 \% \text { vs. } \\
70.6 \%)\end{array}$ \\
\hline & & Soft lens 6-10 yr & 30 & $27.1 \pm 5.9$ & $\begin{array}{l}\text { Decrease by } 133 \\
\text { cells/mm2 }\end{array}$ & $\begin{array}{l}26.9 \% /(.33 \text { vs. } \\
.26)\end{array}$ & $\begin{array}{l}19.5 \% /(59.1 \% \text { vs. } \\
70.6 \%)\end{array}$ \\
\hline & & Soft lens $>10 \mathrm{yr}$ & 30 & $30.7 \pm 7.1$ & $\begin{array}{l}\text { Decrease by } 289 \\
\text { cells } / \mathrm{mm} 2\end{array}$ & $\begin{array}{l}26.9 \% /(.33 \text { vs. } \\
.26)\end{array}$ & $\begin{array}{l}27.4 \% /(55.4 \% \text { vs. } \\
70.6 \%)\end{array}$ \\
\hline
\end{tabular}

C-S is cross sectional study, $\mathrm{P}$ is prospective study.

Table 1.2 Corneal Endothelial Cell Changes Caused by Contact Lens Wear 


\subsubsection{Age}

More than one aspect of corneal endothelial cell morphology has been found to be related to age. Bourne et al. in a 10-year longitudinal study of 42 adult subjects found that there was $0.6 \% \pm 0.5 \%$ corneal endothelial cell loss per year (Bourne 1996). The percentage of hexagonal cells also decreases as a function of age (Carlson, Bourne et al. 1988). Nucci et al estimated that in children there is a rapid decrease of corneal endothelial cell density of $13 \%$ between ages 5 and 7 years, and there is further decrease of $12 \%$ by age 10 years (Nucci, Brancato et al. 1990). Laing studied 61 subjects age from 20 to 89 years and found there was $0.1 \%$ per year increase in corneal endothelial area (Laing, Sandstrom et al. 1976). Other researches also found that aging is related to corneal endothelial morphology (Laing, Sandstrom et al. 1976; Hoffer and Kraff 1980; Cheng, Jacobs et al. 1985; Yee, Matsuda et al. 1985; Muller, Doughty et al. 2000). Because age is related to corneal endothelial morphology, there should be interactions between age and other factors such as contact lens wear in causing corneal endothelial cell morphology change. Researchers should always consider age as a confounding factor when designing research on corneal endothelial morphology change.

\subsubsection{Intraocular surgery}

Many studies have found that cataract surgery and intraocular lens implantation can cause corneal endothelium morphology change (Bourne and Kaufman 1976; Matsuda, Suda et al. 1984; Ventura, Walti et al. 2001; Ishikawa 2002; Lundberg, Jonsson et al. 2005). Although cataract surgery has been improved greatly and modern phacoemulsification surgery has been widely used, the corneal endothelial cell 
morphology change could still be found, and in general, there is more change in endothelial cell density than in coefficient of variation and percentage of hexagonal cells change (Ishikawa 2002; Bourne, Minassian et al. 2004; O'Brien, Fitzpatrick et al. 2004; Lundberg, Jonsson et al. 2005; Milla, Verges et al. 2005). Other ocular surgeries, such as a glaucoma drainage and surgery instruments sterilized by plasma gas can also cause corneal endothelial cell damage (Smith, Khoury et al. 2000; Lim 2003).

\subsubsection{Refractive surgery}

Laser in situ keratomileusis (LASIK) has been used to correct myopia. Acute corneal endothelium morphology changes including pleomorphism and loss of hexagonality have been found after Laser in situ keratomileusis (Kim, Sorenson et al. 2001) while long term corneal endothelium morphology changes have not been found (Perez-Santonja, Sakla et al. 1997; Jones, Azar et al. 1998; Kim, Sorenson et al. 2001).

\subsubsection{Corneal endothelial disorders}

Some corneal endothelial disorders, such as Fuchs' endothelial dystrophy, proliferative endotheliopathies, and posterior polymorphous dystrophy, have been associated with change in corneal endothelial morphology (Waring, Bourne et al. 1982). 


\subsubsection{Eye disease}

Studies have found eye diseases such as glaucoma (Vannas, Setala et al. 1977;

Gagnon, Boisjoly et al. 1997; Sihota, Lakshmaiah et al. 2003), and eye trauma (Waring, Bourne et al. 1982) can cause corneal endothelial morphology change. In glaucoma patients, there are significantly less corneal endothelial cells than control subjects.

\subsubsection{Systemic disease}

Some systemic diseases such as diabetes mellitus (Schultz, Matsuda et al. 1984; Schultz, Matsuda et al. 1985; Matsuda, Ohguro et al. 1990; Keoleian, Pach et al. 1992; Inoue, Kato et al. 2002), and chronic renal failure (Ohguro, Matsuda et al. 1999) can cause corneal endothelial cell morphology changes.

1.6 The role of refractive error in corneal endothelial morphology change

In the United States, it is estimated that myopia (nearsightedness) affects $25 \%$ of the population (Sperduto, Seigel et al. 1983). High levels of myopia are associated with increased risk of cataract (Lim, Mitchell et al. 1999; Younan, Mitchell et al. 2002), posterior vitreous detachment, retinal tears and retinal detachment (Ogawa and Tanaka 1988), increased risk of choroidal neovascularization (Grossniklaus, Hutchinson et al. 1994), and myopic macular degeneration (Vongphanit, Mitchell et al. 2002). In spite of an impressive body of research, little is known about the effect of myopia on the cornea, particularly the corneal endothelium. The status of the corneal endothelium in myopia is important for a number of reasons: 
1. Highly myopic patients are at greater risk of developing cataracts and thus undergo cataract surgery more often than less (or non-) myopic patients (Younan, Mitchell et al. 2002). It is well established that the integrity of the corneal endothelium is important for successful visual outcomes following cataract surgery. It is also known that cataract surgery may cause endothelial cell damage (Bourne, Nelson et al. 1994). Even though the phacoemulsification procedure used in conventional cataract surgery has been improved greatly and new viscoelastic materials have been produced, endothelial cell damage is still a risk. A healthier preoperative corneal endothelium may resist the insult of surgery and may have a better postoperative prognosis (Rao, Aquavella et al. 1984).

2. Highly myopic patients are more likely to choose contact lenses and refractive surgery. It is well established that contact lenses affect the endothelium (Holden, Sweeney et al. 1985; MacRae, Matsuda et al. 1985; MacRae, Matsuda et al. 1986; Carlson and Bourne 1988; Carlson, Bourne et al. 1988; MacRae, Matsuda et al. 1994; Setala, Vasara et al. 1998; Bourne, Holtan et al. 1999; Wiffen, Hodge et al. 2000; Lee, Park et al. 2001). Although the change in endothelial density is modest, changes in the regularity (size and shape) of the cell mosaic are well established. The effects of various refractive surgery procedures on the cornea are more uncertain. In photorefractive keratectomy and LASIK (Stulting, Thompson et al. 1996; Jones, Azar et al. 1998; Collins, Carr et al. 2001) the corneal endothelium appears to be relatively unaffected. In contrast, newer technologies including intraocular lenses for myopia, e.g. the Staar Implantable Contact Lens, appear to produce small but continuing reductions in corneal endothelial cell density in patients receiving the device (Edelhauser, Sanders et al. 2004). 
3. The above factors may combine and have interactions. There are many highly myopic patients who have worn contact lenses for a long time, and it is very likely that older myopic people wear contact lens longer than young myopic people. Therefore, for those who are now at an age when cataracts develop, it is very important to know the corneal endothelium status of these patients given their higher probability of undergoing cataract surgery. Using results of previous studies which failed to investigate all possible risk factors and interactions between risk factors could not achieve a reliable prediction of the endothelial status for these patients.

As stated above, contact lenses are one of the major methods of optically correcting myopia. Both soft contact lenses and rigid contact lenses have been found to cause corneal endothelial changes, such as endothelial cell density and cell shape changes. This change is more significant in those subjects who have worn contact lenses for a longer time. However, the refractive status of the subjects in those contact lens studies is not clear. Indeed, endothelial cell changes after long-term contact lens wear in high myopia ( $-6 \mathrm{D}$ or more myopia) patients have never been studied.

Likewise, the effects of age on the corneal endothelium are unclear. Natural history studies of the corneal endothelium are rare. For example, the often-quoted value of $0.6 \%$ loss in corneal endothelium per year comes from a cohort study of 52 subjects (Bourne, Nelson et al. 1997). Most of the published data come from cross-sectional studies, but the 
confounding effects of contact lens wear are often not reported (Hoffer and Kraff 1980; Cheng, Jacobs et al. 1985; Yee, Matsuda et al. 1985). The uncertainty regarding the effects of high myopia, aging, long-term contact lens wear and their interactions make it challenging for practitioners to assess the safety of emerging technologies for the correction of refractive error. Furthermore, a number of instruments are available to photograph the corneal endothelium and analyze its morphology, but their equivalence to each other has not been investigated. A large-scale cross-sectional study was thus proposed.

We hypothesize that highly myopic patients show greater age-related changes in endothelial cell density, polymegethism (variation in size), and pleomorphism (variation in shape). The objectives of the research are:

- To investigate the effects of age, race, gender, contact lens wear and refractive error on corneal endothelial morphology.

- To evaluate possible interactions between all above factors on their influence on corneal endothelial morphology change.

- To compare the endothelial cell measurement using two instruments: the ConfoScan3 and the Konan KSS-300. 


\section{CHAPTER 2}

\section{MATERIALS AND METHODS}

\subsection{Subjects}

A total of 149 subjects were recruited. The majority of the subjects were faculty, staff, and students of The Ohio State University or patients of the contact lens clinic of The Ohio State University College of Optometry. An advertisement was used to introduce the research study to all subjects. Subjects with active eye disease, a history of serious eye injury, eye surgery (except refractive surgery), or diabetes were excluded from the study.

The tenets of the Declaration of Helsinki were followed throughout the study. The Ohio State University Office of Research Risk Protection’ Biomedical Sciences Institutional Review Board approved the protocol. Written informed consent was obtained from all subjects after the protocol and possible risks had been explained.

\subsection{Instruments}

2.2.1 Noncon Robo Pachy and KSS-300 Image Storage System

The Noncon Robo Pachy Model SP-9000LC specular microscope (Konan Medical Corporation, Fairlawn, New Jersey) was used to record the central corneal endothelial 
image. The Konan Nocon Robo Pachy is a non-contact microscope and camera. It captures a specular image of the corneal endothelium and measures the corneal thickness.

During the examination, each subject was asked to put his or her chin on the chin rest and look at the internal fixation targets. After adjusting the chin rest until it was verified on the monitor screen that the subject was looking at the fixation target, the corneal endothelium image was recorded.

After recording the corneal endothelium image using the Noncon Robo specular microscope, a KSS-300 Image Storage System (Konan Medical Corporation, Fairlawn, New Jersey) was used to capture and save the image from the Noncon Robo specular microscope. The KSS-300 Image Storage System was later used to analyze the corneal endothelial image.

\subsubsection{Confoscan3}

A ConfoScan3 confocal microscope (NIDEK Technologies, Vigonza, Italy) was also used to photograph the corneal endothelium. The Confoscan3 is a contact digital microscope that records a sequence of corneal endothelium images.

Before the examination, an anesthetic eye drop was put into the examined eye, and then the subject was asked to put the chin on the chin rest. A pea-sized drop of eye 
ointment was applied to the tip of the probe. The joystick was moved to align the microscope with the subject's eye. After alignment was achieved, the corneal endothelial image recording was started.

After recording a sequence of corneal endothelium images, the examiner reviewed the images and then saved images in the same Confoscan 3 computer system.

Confoscan3 comes with Endothelial Cell Analysis Software. The cell count software was later used to perform automatic, semi-automatic, and manual analysis of the recorded corneal endothelial images.

\subsection{Testing Protocol}

Each subject attended for one test session that lasted less than 25 minutes. The following procedures were performed:

1. Subjects were asked to remove contact lenses if they wore them.

2. Two endothelial cell images of the subject's right eye were captured using the Konan Nocon Robo Pachy.

3. Topical anesthesia was achieved in both eyes with $0.5 \%$ proparcaine hydrochloride solution. One drop was instilled in each eye. Measurements were made on only the right eye, but numbing both eyes helped reduce reflex blinking during the photography.

4. Endothelial images were taken of the right eye using the ConfoScan3. A pea-sized drop of GenTeal lubricant eye gel (Novartis Ophthalmic) was placed on the lens 
of this instrument, and this gel came into contact with the front of the right eye during the examination.

All the above procedures were performed by the same examiner.

\subsection{Image analysis}

The KSS-300 and Confoscan3 software were used to analyze the images taken by the Konan Nocon Robo Pachy and Confoscan3 respectively. One examiner analyzed all Konan Nocon Robo Pachy images, while a different examiner analyzed all Confoscan3 images.

\subsubsection{KSS-300 image analysis}

One endothelial image with the most visible cells from each subject was selected and analyzed by the KSS-300 image analysis system. After picking the image, the "Analysis" box on the main menu was chosen, prompting an analysis screen to pop up. Then a left click of the mouse placed a green dot at the center of each cell. As many contiguous cells as possible were dotted, and no cells were omitted in the middle of the whole group. After the dotting was finished, the "End" box was clicked, and the main screen appeared with the results of the analysis. The results of the KSS300 image analysis include:

- Corneal endothelial cell density (ECD): cell density, which is the number of cells per square millimeter. i.e., 3000 means 3000 cells per square millimeter.

- Coefficient of variation (CoV). 
- Percentage of Hexagonal cells (\%Hex).

- Average cell size of the cells dotted in square microns (AVE).

- The actual number of cells that are used by the KSS-300 to generate the results (NUM).

- Standard deviation (SD). Ideal number is 140 or lower (KSS-300 manual)

\subsubsection{Confoscan3 Endo Cell Analysis Software}

The Confoscan3 comes with endothelial cell analysis software that analyzes the corneal endothelial images automatically, semi-automatically (using tools provided by the software to edit the incorrectly counted cells by an automatic method), and manually. When using the automatic or semi-automatic cell count method, a region of interest (ROI) is selected by the software with a green dotted square on the image. The region of interest that the examiner chooses should be inside the softwareselected region of interest to make sure that all cells inside the region of interest are counted.

The results panel of the semi-automatic cell count is the same as the results panel of the automatic cell count. The following information is shown on the results panel:

- Corneal endothelial cell density (ECD) in the number of cells/ $\mathrm{mm}^{2}$.

- Area $\left(\mu \mathrm{m}^{2}\right)$ : the mean cell area with its standard deviation and coefficient of variation.

- Sides: the mean cell sides with its standard deviation, coefficient of variation and the percentage of hexagonal cells. 
- Number of counted cells.

- Region of interest area in $\mathrm{mm}^{2}$.

- Valid area in $\mathrm{mm}^{2}$ : the sum of the areas of all counted cells.

- Cell area in $\mu \mathrm{m}^{2}$ : the area of a cell that is highlighted by the mouse pointer within the region of interest.

The Confoscan 3 endothelial cell analysis software provides four editing tools that can be used to correct the incorrectly counted cells using automatic method. The tools enable the operators to:

- Fuse two or more cells,

- Move/delete/add cell vertices,

- Cut a cell into two, and

- Erase one or more cells.

The manual cell count method allows the examiner to choose an ROI independent of the software-selected ROI. The cells inside the ROI are dotted manually using the mouse. The results panel of the manual cell count has less information than the results panel of the automatic cell count result, there is no information about coefficient of variation and percentage of hexagonal cells:

- Corneal endothelial cell density (ECD): the number of cells/ $\mathrm{mm}^{2}$.

- Area in $\mu \mathrm{m}^{2}$.

- Distance: the distance between two points of the region of interest. 
- Number of counted cells.

- Region of interest area in $\mathrm{mm}^{2}$.

- Valid area in $\mathrm{mm}^{2}$ : the sum of the areas of all counted cells.

- Cell area in $\mu \mathrm{m}^{2}$ : the area of a cell that is highlighted by the mouse pointer within region of interest.

\subsection{Data Analysis}

Outcome (dependent) variables for this study are:

- Corneal endothelial cell density (the number of cells $/ \mathrm{mm}^{2}$ ),

- Coefficient of variation (polymegathism/ CoV),

- Percentage of hexagonal cells (pleomorphism/\%Hex).

The above three aspects of corneal endothelial morphology were analyzed separately.

The independent variables were as follows:

- Age (in years),

- Contact lens wearing time (in years),

- Refractive error (in diopter),

- Gender,

- Race.

Gender (male and female) and race (White, Black, Hispanic, and Asian) were categorical variables. Because there were only 5 Black subjects and 2 Hispanic subjects in our study, and the number is not enough for each of them to be put into an individual 
group, we therefore put Black and Hispanic subjects into White group as a non-Asian group. Indicator variables were created for gender and race: male was used as the reference group for gender and non-Asian was used as the reference group for race.

SPSS 13.0 statistical software package was used to analyze the data. Linear regression was used to determine whether age, contact lens wearing time, refractive error, gender, and race could be used to predict corneal endothelial cell density, $\mathrm{CoV}$ and $\% \mathrm{Hex}$. The stages of data analysis were as follows:

1. Descriptive analysis: Mean and SD were calculated for each variable. Each dependent variable was plotted as a function of each independent variable. i.e., univariate scatterplots were created for corneal endothelial cell density, coefficient of variation and percentage of hexagonal cells versus age, years of contact lens wear, refractive error, race, and gender.

2. Simple linear regression models were fitted for each independent variable. Normality, linearity, and equal variance were checked for each model. Normality was checked using a histogram and a normal probability plot of the residuals. If the normality assumption was met, all points in the residual scatterplot should have clustered tightly in the center of the plot at each level of the predicted score. The ideal normal distribution should look like a straight line, which is rarely observed. Normal Probability Plots are also samplesize dependent. The larger the sample size, the more normal the data should appear on the plot. Linearity was checked using residual versus predicted value plots. If the linearity 
assumption was met, a horizontal scatter of residuals should have been seen. Equal variance was checked using studentized residuals versus predicted values plot. If the equal variance assumption was met, the scatter of the residuals about the center of the plot should have been the same at all predicted values and there should have been no outliers.

3. Coefficients, SE, p-values, mean square error (MSE), and adjusted $\mathrm{R}^{2}$ from each simple linear regression model were evaluated. The independent variables for all simple linear models were: age, years of contact lens wear, degree of myopia, gender (Female), and race (Asian). The adjusted $\mathrm{R}^{2}$ was used to determine which independent variable should be selected in the model. The significant variable that yielded the highest $\mathrm{R}^{2}$ and smallest MSE was the first factor that was selected to build the multivariate model.

4. A multivariate model was built by adding significant independent variables with the second highest adjusted $\mathrm{R}^{2}$ and then the next highest and so on. As long as the adjusted $\mathrm{R}^{2}$ increased and the variable was significant, this procedure could be continued. When the adjusted $\mathrm{R}^{2}$ no longer increased, no further independent variable were added and the model was the best model.

5. Plausible biological interactions were evaluated. Among the independent variables studied in this research were the interaction between age and years of contact lens wear, 
the interaction between age and degree of myopia, the interaction between years of contact lens wear and the degree of myopia, and the interaction between race (Asian) and degree of myopia.

6. After the final models were built for corneal endothelial cell density, coefficient of variation, and percentage of hexagonal cells respectively, the model assumptions, including normality, linearity, and equal variance, were evaluated again. 


\section{CHAPTER 3}

\section{RESULTS}

A total of 149 subjects were recruited. Table 3.1 and Table 3.2 present the descriptive statistics for the continuous independent variables, including age, years of contact lens wear, and refractive error. Table 3.3 presents the descriptive statistics for the categorical variables, including gender and race. Table 3.4 presents information of the patients' contact lens type. Because there were only 5 Black subjects and 2 Hispanic subjects, the number is not large enough for any statistical analysis as a single group for Black and Hispanic; therefore, we divided subjects into Asian and Non-Asian groups by putting Black and Hispanic together with White into the Non-Asian group.

\begin{tabular}{lcccc}
\hline & Minimum & Maximum & Mean & SD \\
\hline Age (years) & 19 & 71 & 33 & 11 \\
Years of contact & 0 & 40 & 8.7 & 9.7 \\
lens wear & -12.00 & +3.75 & -4.11 & 3.03 \\
Refractive error (D) & & & & \\
\hline
\end{tabular}

Table 3.1 Descriptive Statistics of Age, Years of Contact Lens Wear, and Refractive Error 


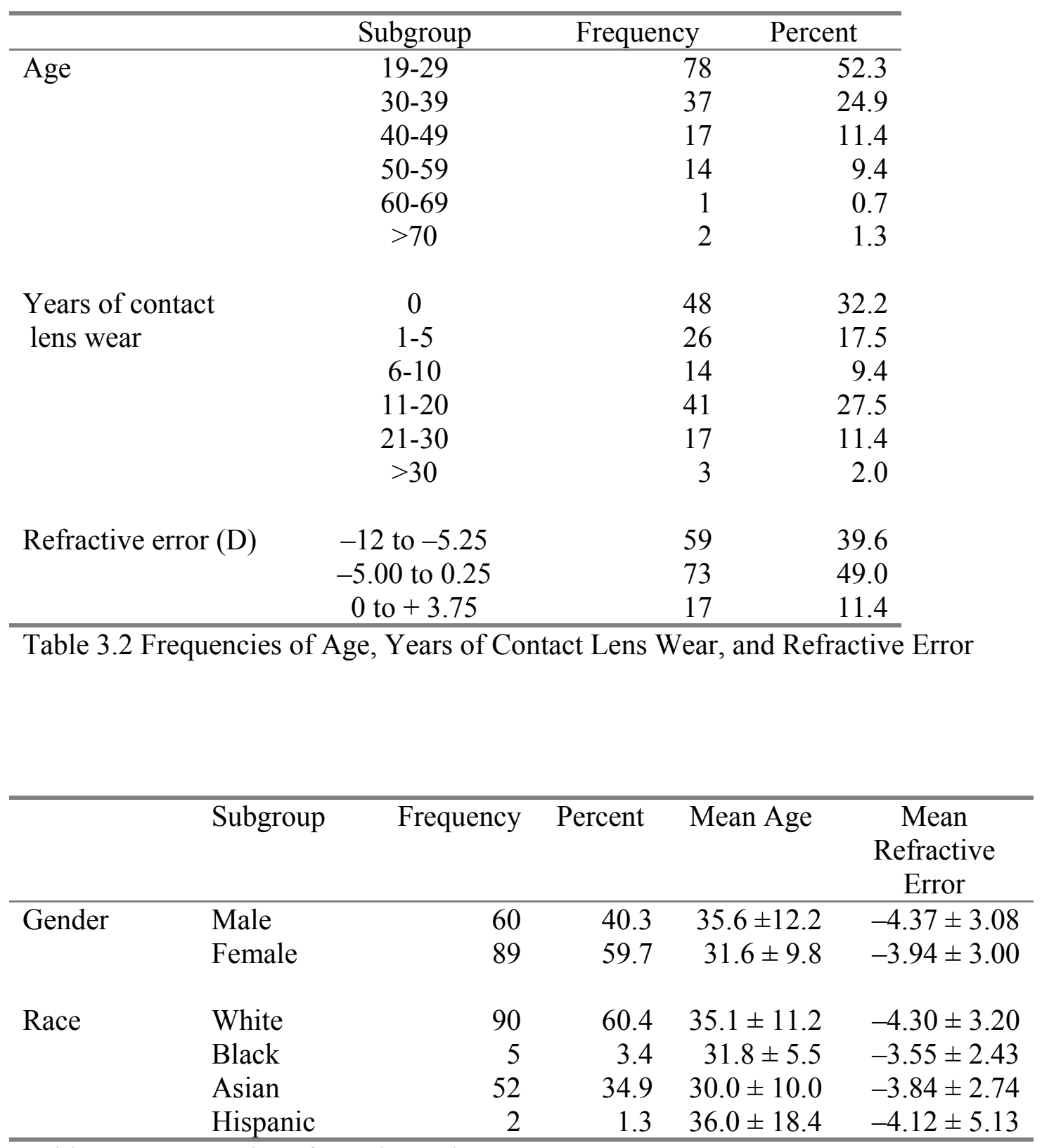

Table 3.3 Frequencies of Gender and Race 


\begin{tabular}{lrrrr}
\hline & Frequency & Percent & Mean Age & $\begin{array}{c}\text { Mean } \\
\text { Refractive } \\
\text { Error }\end{array}$ \\
\hline None & 48 & 32.2 & $34.1 \pm 13.2$ & $-2.05 \pm 2.81$ \\
Soft & 83 & 55.7 & $31.2 \pm 9.2$ & $-4.82 \pm 2.50$ \\
RGP & 16 & 10.7 & $38.6 \pm 8.5$ & $-6.55 \pm 2.85$ \\
PMMA & 2 & 1.3 & $51 \pm 9.9$ & $-4.87 \pm 3.71$ \\
\hline
\end{tabular}

Table 3.4 Frequencies of Current Contact Lens Type

\subsection{Regression Model of Corneal Endothelial Cell Density}

The mean endothelial cell density (ECD) for all 149 subjects was $2912 \pm 347$ cells $/ \mathrm{mm}^{2}$.

\subsubsection{Scatterplots for Corneal Endothelial Cell Density}

Figures 3.1 to Figure 3.5 are the univariate scatterplots of corneal endothelial cell density versus the five independent variables: age, years of contact lens wear, refractive error, gender, and race. There is a trend for ECD to decrease with age and with years of contact lens wear. There is no obvious relationship between corneal endothelial cell density and refractive error. In the scatterplot of the two indicator variables, gender and race, there is a trend that females have a higher ECD than males, and Asians have a higher ECD than Non-Asians.

\subsubsection{Univariate Regression Analysis}

Table 3.5 is the summary of all univariate regression analyses for corneal endothelial cell density versus each of the five independent variables. Age, years of contact lens 
wear, gender, and race are all significantly correlated with corneal endothelial cell density. Refractive error, however, is not correlated with endothelial cell density. The model with age is the best univariate model, with the highest adjusted $\mathrm{R}^{2}$ of .197 and lowest mean square error (MSE) of 97793.

\begin{tabular}{lrrrrr}
\hline & \multicolumn{1}{c}{$\beta$} & \multicolumn{1}{c}{ SE } & \multicolumn{1}{c}{$\mathrm{p}$} & \multicolumn{1}{c}{ MSE } & Adjusted R $^{2}$ \\
\hline Age & -14.069 & 2.349 & $<.001$ & 97793 & .197 \\
CL years & -6.894 & 2.895 & .019 & 117143 & .031 \\
Refractive error & -7.942 & 9.349 & .401 & 121080 & .002 \\
Female & 150.387 & 56.929 & .009 & 116149 & .039 \\
Asian & 226.532 & 56.964 & $<.001$ & 109845 & .091 \\
\hline
\end{tabular}

Table 3.5 Summary of Univariate Models of Endothelial Cell Density

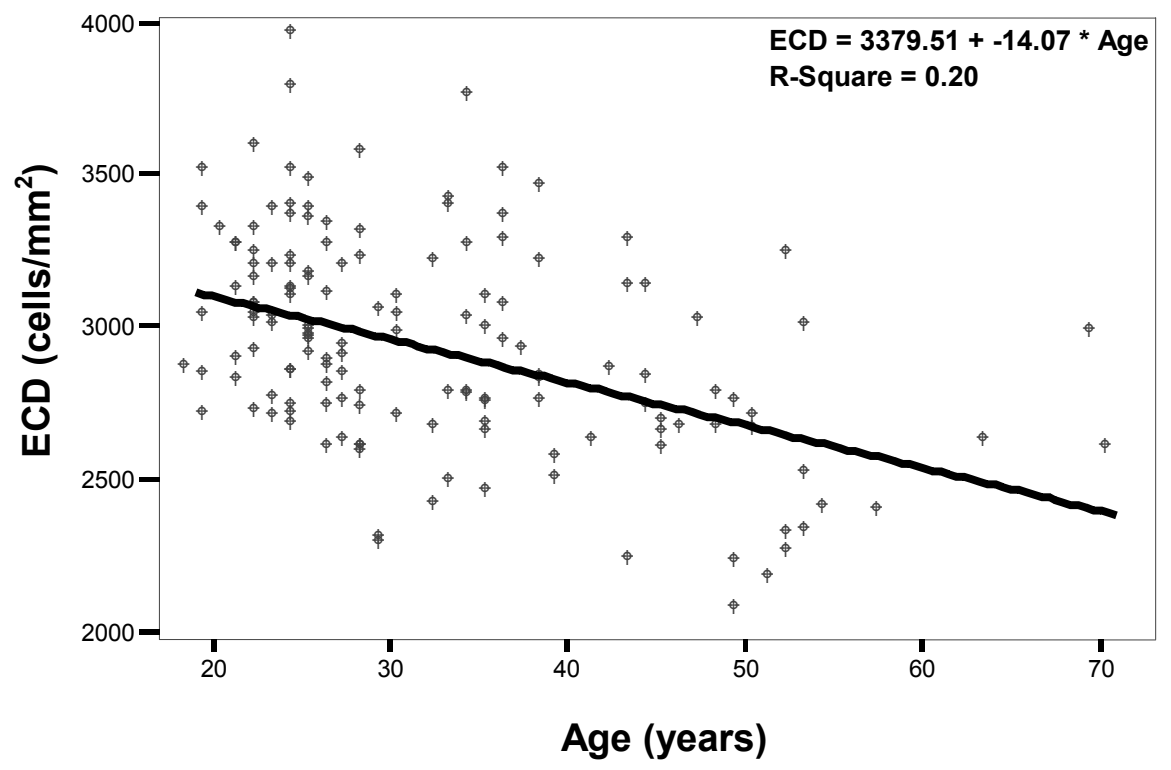

Figure 3.1 Scatterplot of Endothelial Cell Density versus Age 


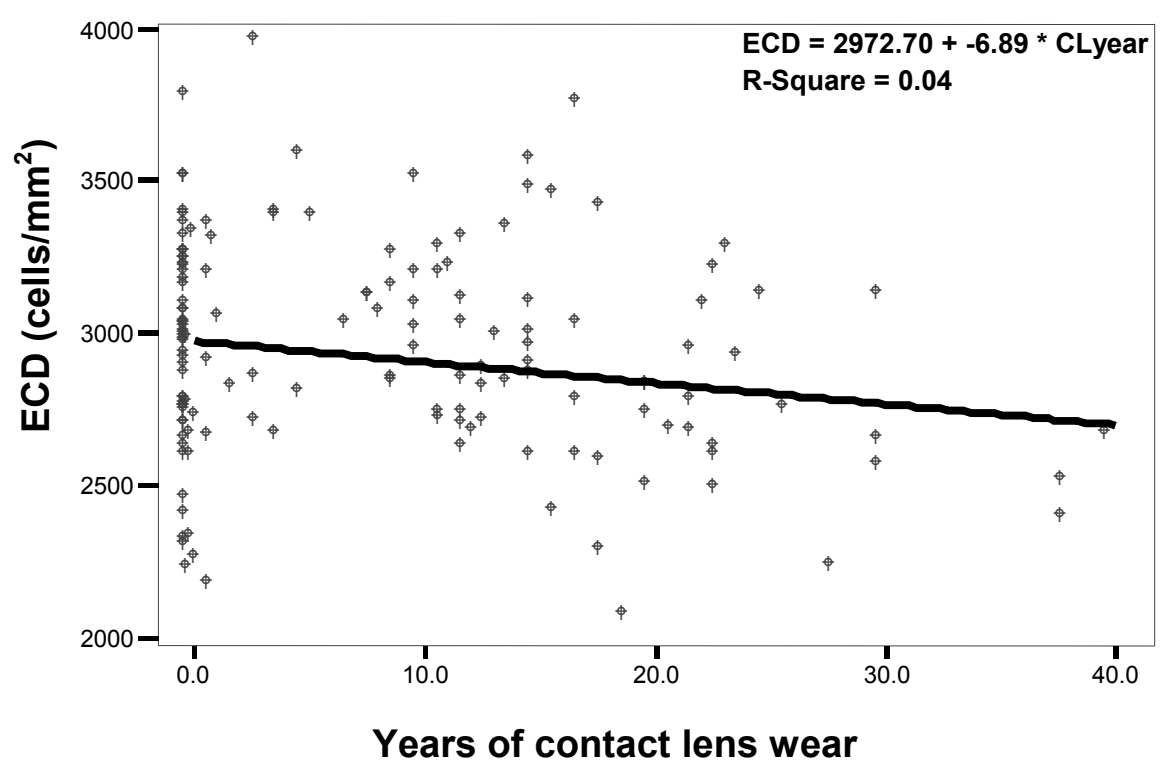

Figure 3.2 Scatterplot of Endothelial Cell Density versus Years of Contact Lens Wear

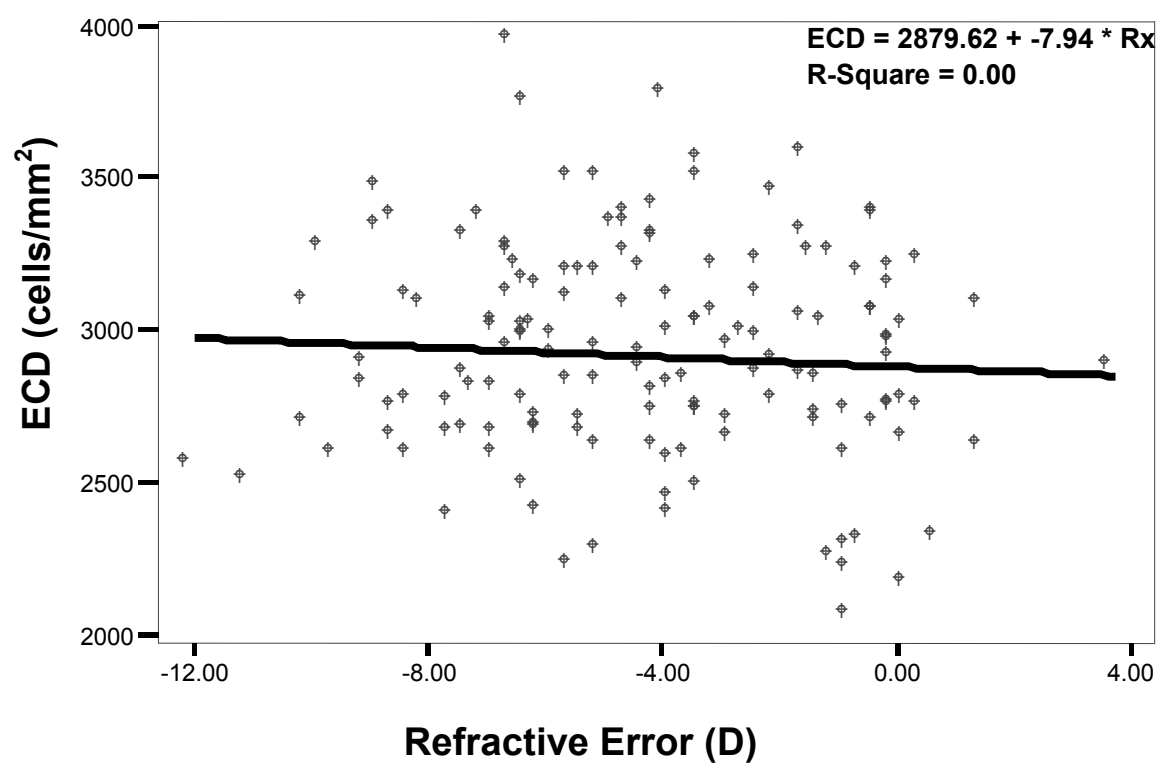

Figure 3.3 Scatterplot of Endothelial Cell Density versus Refractive Error 


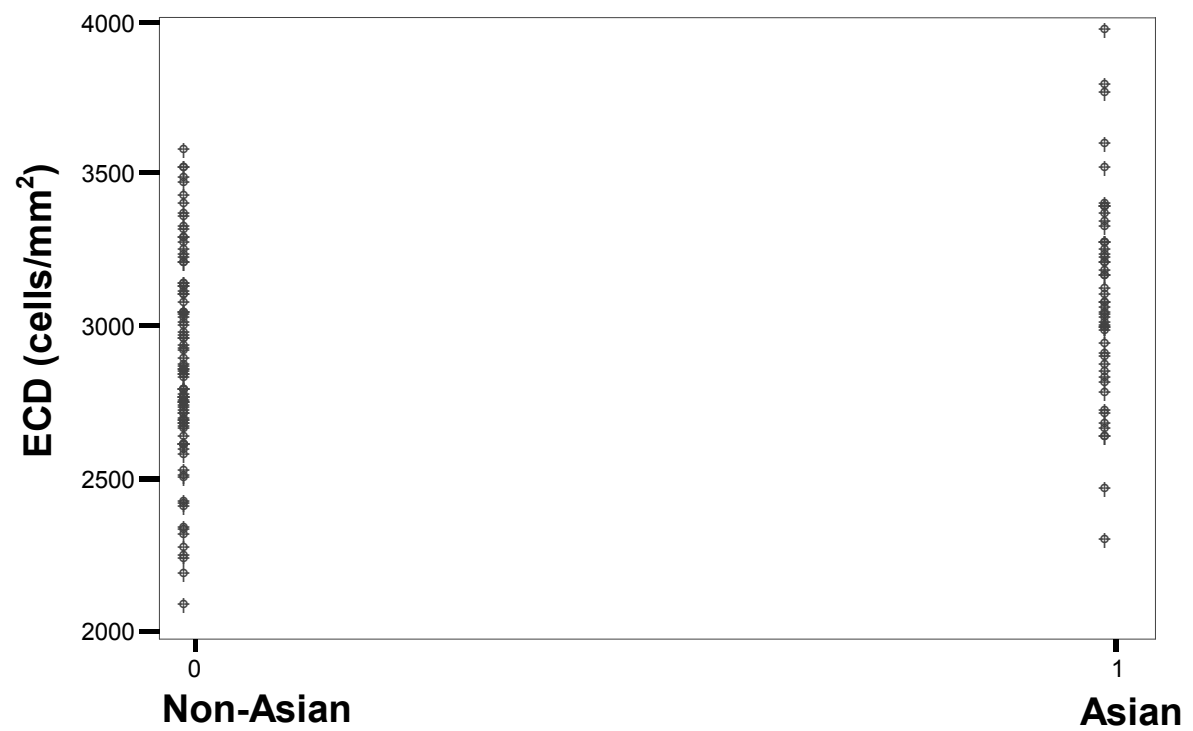

Figure 3.4 Scatter plot of Endothelial Cell Density versus Race

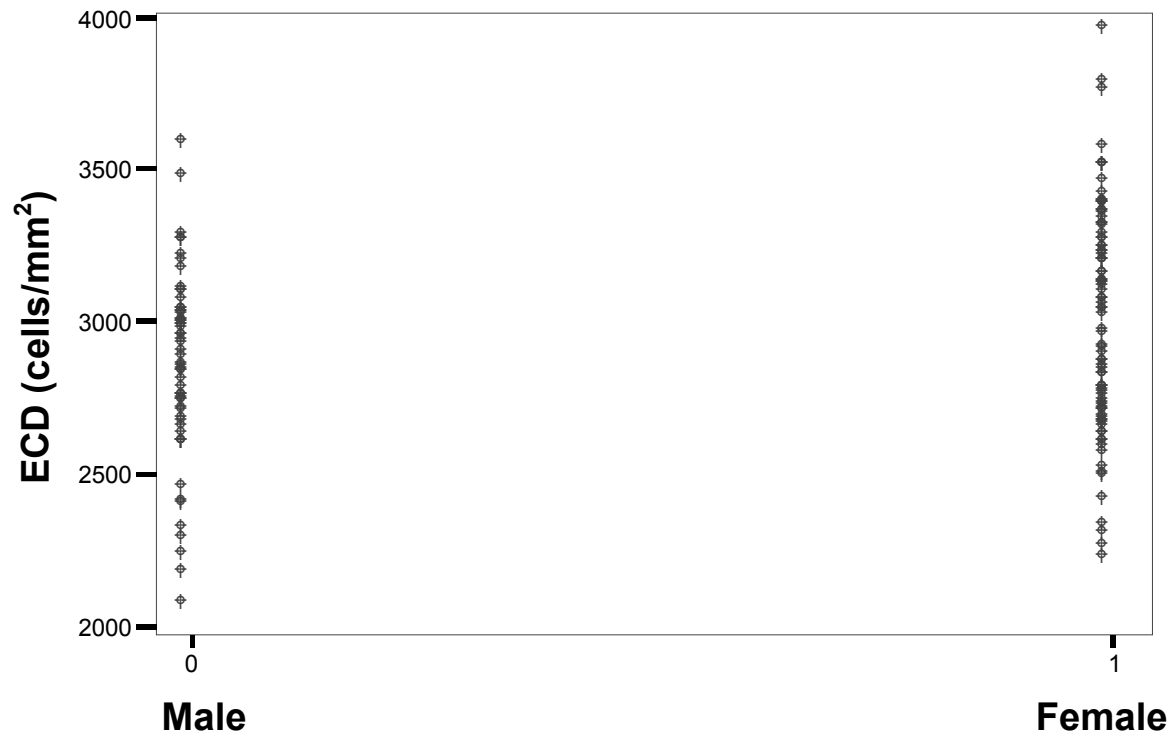

Figure 3.5 Scatterplot of Endothelial Cell Density versus Gender 


\subsubsection{Checks on Model Assumptions}

Figures in the appendix are checks of the assumptions underlying the linear model for endothelial cell density versus all significant independent variables. Histogram and Normal probability plots check for normality assumption. The scatterplot of unstandardized residuals versus predicted values checks for linearity. The scatterplot of studentized residuals versus predicted values checks for outliers, i.e, the assumption of equal variance.

Table 3.6 is the summary of model assumptions checks. Results showed that normality, linearity, and equal variance assumptions were not violated in any of the univariate models. Therefore we do not need to perform any data transformation prior to linear regression analysis.

\begin{tabular}{llll}
\hline Variable & Normality & Linearity & Equal Variance \\
\hline Age & Yes & Yes & Yes \\
CL years & Yes & Yes & Yes \\
Female & Yes & Yes & Yes \\
Asian & Yes & Yes & Yes \\
\hline
\end{tabular}

Table 3.6 Checks on Model Assumption for Endothelial Cell Density

\subsubsection{Multiple Regression Model Construction}

All significant factors from univariate analysis were used to build the multiple regression model. Because the univariate model with age had the highest adjusted $\mathrm{R}^{2}$ of 
.197, age was chosen first, then race (Asian), gender (female), and finally years of contact lens wear were added individually after adjusting for age. Table 3.7 is the summary of model built with age.

\begin{tabular}{llllll}
\hline & $\beta$ & SE & $p$ & MSE & Adjusted R2 \\
\hline Asian & 164.85 & 53.52 & .002 & 92455 & .235 \\
Female & 96.12 & 52.73 & .07 & 96272 & .203 \\
CL years & -3.88 & 2.69 & .151 & 97077 & .197 \\
\hline
\end{tabular}

Table 3.7 Summary of Model Built with Age for Endothelial Cell Density

Adding race (Asian) produced the highest increase in the adjusted $\mathrm{R}^{2}$, therefore race was added into the model with age; then gender and years of contact lens wear were added individually. Table 3.8 is the summary of model built with age and race.

\begin{tabular}{llllll}
\hline & $\beta$ & SE & $\mathrm{p}$ & MSE & Adjusted R $^{2}$ \\
\hline Female & 80.08 & 51.72 & .124 & 91579 & .242 \\
CL years & -1.27 & 2.80 & .651 & 92961 & .231 \\
\hline
\end{tabular}

Table 3.8 Summary of Model Built with Age and Race for Endothelial Cell Density

Results showed that when adding gender into the model, the adjusted $\mathrm{R}^{2}$ increased slightly but the $\mathrm{p}$ value was greater than 0.10 , therefore gender should not be included into the multivariate model. Years of contact lens wear was neither significant in the model nor increased the adjusted $\mathrm{R}^{2}$. Hence, years of contact lens wear should not be included in the multivariate model. Therefore, the variables in the model of corneal endothelial cell density are age and race. 


\subsubsection{Evaluation of Interaction}

We did not think there was any biologically reasonable interaction between age and race in this study, therefore we did not check for interaction.

\subsubsection{Model Assumptions Check of the Final Model}

The final model, which includes age and race, should be checked for multiple regression model assumptions. Figures are shown in the appendix. No model assumptions were violated.

The final model for corneal endothelial cell density change is:

$\mathrm{ECD}=3270-12.5 *$ Age $+(164.8$ if Asian $)$

The adjusted $\mathrm{R}^{2}$ for this model is .235 , i.e., $23.5 \%$ of the variability of corneal endothelial cell density change can be explained by this model.

\subsection{Regression Model of Coefficient of Variation}

The mean coefficient of variation $(\mathrm{CoV})$ of all 149 subjects was $33 \% \pm 6.65 \%$.

\subsubsection{Scatterplots of Coefficient of Variation}

Figure 3.6 to Figure 3.10 are the univariate scatterplots of coefficient of variation versus all independent variables: age, years of contact lens wear, refractive error, gender, and race. The coefficient of variation increased with age, years of contact lens wear, and the degree of myopia. No obvious trends were evident for gender or race. 


\subsubsection{Univariate Regression Analysis}

Table 3.9 summarizes the univariate regression analyses for the coefficient of variation versus each of the five independent variables. Age, years of contact lens wear, and refractive error are all significantly correlated with the coefficient of variation. Race and gender, however, are not significant. The model with years of contact lens wear is the best univariate model, with the highest adjusted $\mathrm{R}^{2}$ of .160 and the lowest MSE of 37.142 .

\begin{tabular}{llllll}
\hline & $\beta$ & $\mathrm{SE}$ & $\mathrm{p}$ & $\mathrm{MSE}$ & Adjusted R $^{2}$ \\
\hline Age & .155 & .048 & .002 & 41.63 & .059 \\
CL years & .279 & .052 & .000 & 37.14 & .160 \\
Rx & -.538 & .175 & .003 & 41.84 & .054 \\
Female & .927 & 1.11 & .406 & 44.31 & -.002 \\
Asian & -.976 & 1.14 & .395 & 44.30 & -.002 \\
\hline
\end{tabular}

Table 3.9 Summary of Univariate Models of Coefficient of Variation

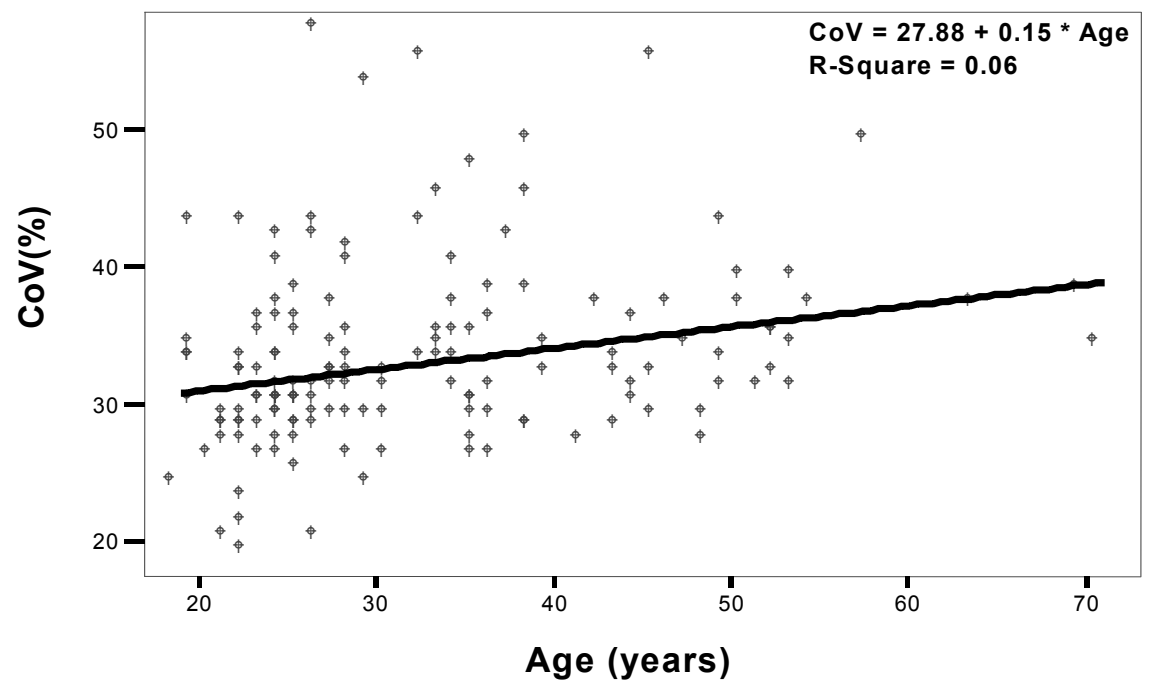

Figure 3.6 Scatterplot of Coefficient of Variation versus Age 


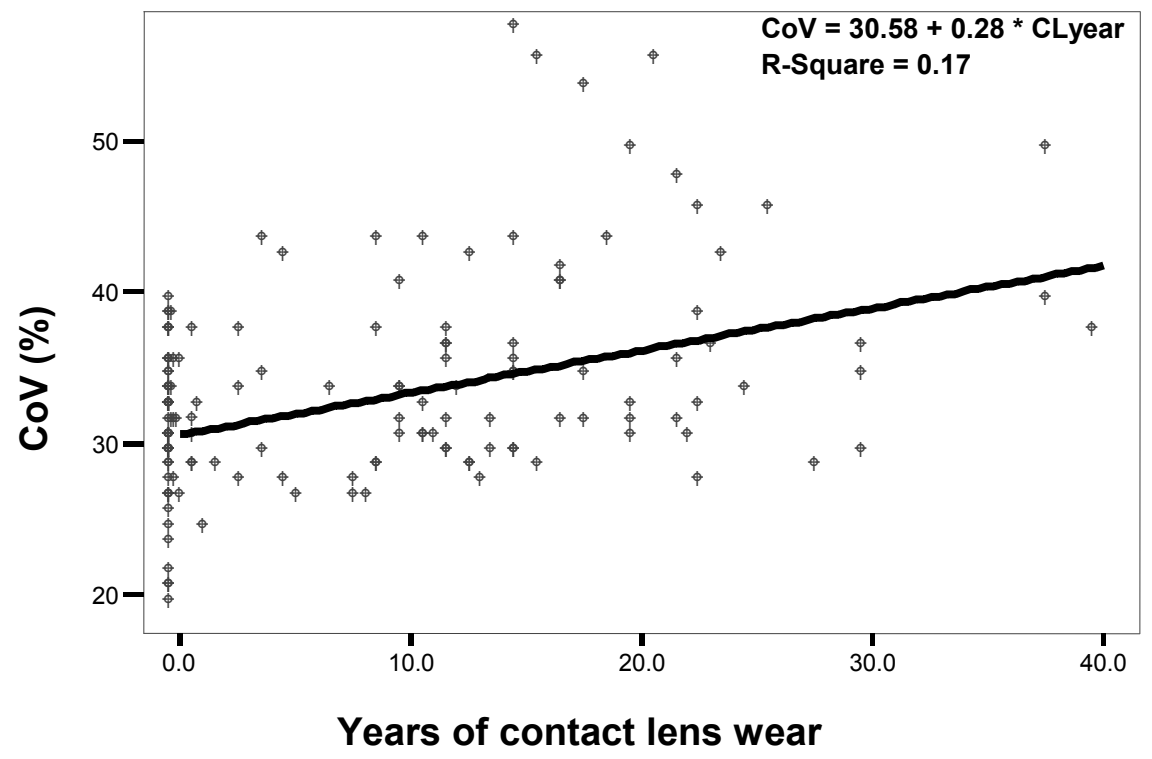

Figure 3.7 Scatterplot of Coefficient of Variation versus Years of Contact Lens Wear

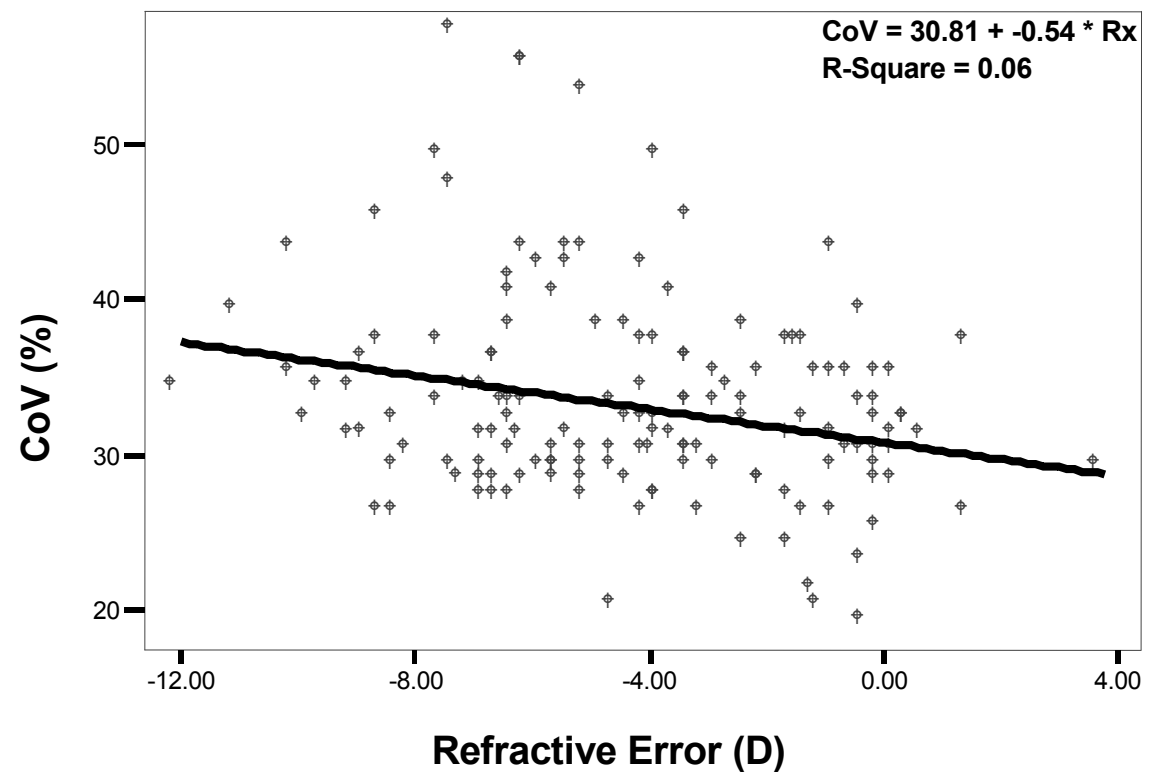

Figure 3.8 Scatterplot of Coefficient of Variation versus Refractive Error 


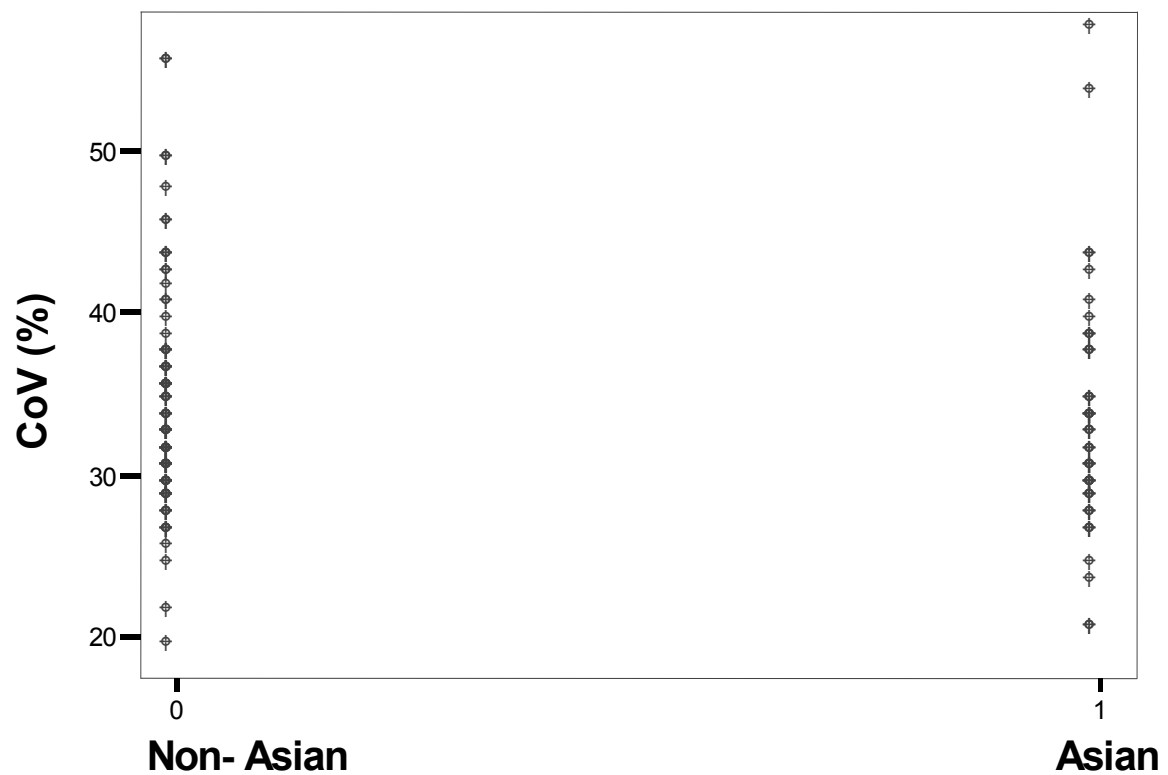

Figure 3.9 Scatterplot of Coefficient of Variation versus Race

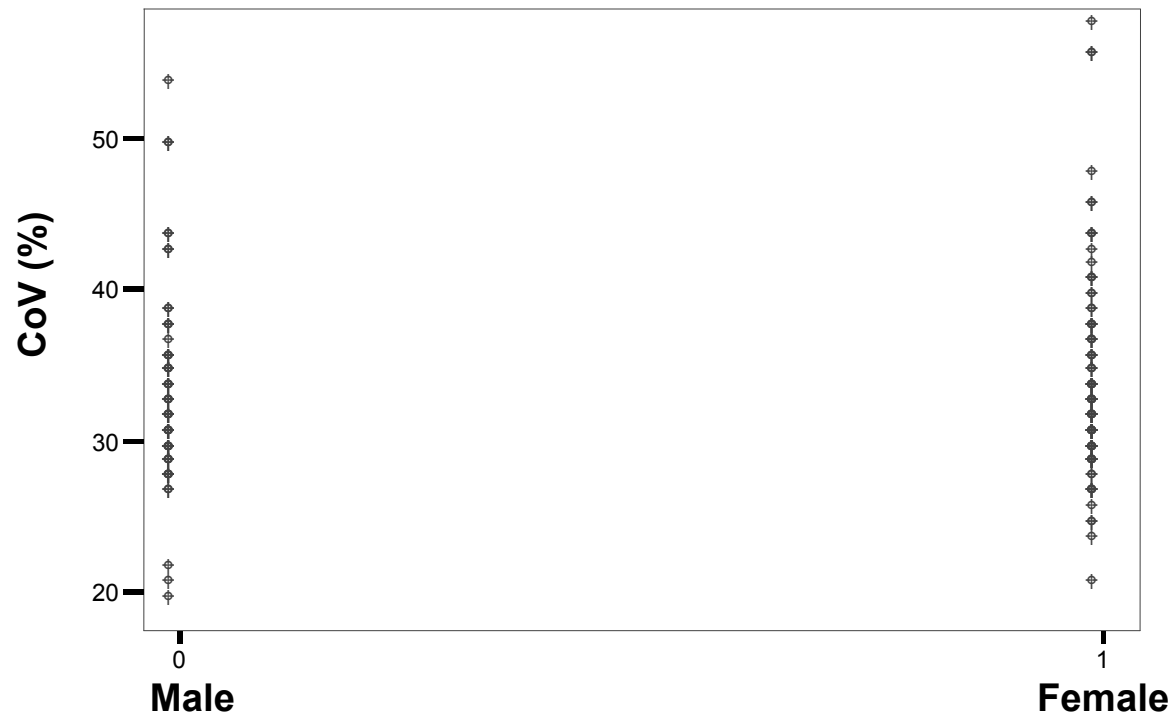

Figure 3.10 Scatterplot of Coefficient of Variation versus Gender 


\subsubsection{Checks on Model Assumptions}

Figures 3.11 to 3.15 are checks of the assumptions underlying linear models on coefficient of variation versus all significant independent variables. Histogram and Normal probability plots check for normality assumption. The scatterplot of unstandardized resiuduals versus predicted values checks for linearity. The scatterplot of studentized residuals versus predicted values checks for outliers, i.e., the assumption of equal variance.

Table 3.10 is the summary of model assumption checks. Results showed that linearity, and equal variance assumptions were not violated in univariate models of age, years of contact lens wear, and refractive error with coefficient of variation. The normal probability plots showed near-normal distribution. Therefore we do not need to perform any data transformation prior to linear regression analysis.

\begin{tabular}{llll}
\hline Variable & Normality & Linearity & Equal Variance \\
\hline Age & Yes- near normal & Yes & Yes \\
CL years & Yes- near normal & Yes & Yes \\
Rx & Yes- near normal & Yes & Yes \\
\hline
\end{tabular}

Table 3.10 Checks on Model Assumption for Coefficient of Variation 


\subsubsection{Multiple Regression Model Construction}

All significant factors in the univariate regression analysis were used to build the multiple regression model. Because years of contact lens wear had the highest adjusted $\mathrm{R}^{2}$ of .160 and lowest MSE, years of contact lens wear was included first. Two separate models were then built by adding age and refractive error respectively. Results are shown in Table 3.11.

\begin{tabular}{llllll}
\hline & $\beta$ & SE & $p$ & MSE & Adjusted R2 \\
\hline Age & .110 & .046 & .018 & 35.99 & .186 \\
Rx & -.118 & .192 & .541 & 37.30 & .157 \\
\hline
\end{tabular}

Table 3.11 Summary of Model Built with Years of Contact Lens Wear for Coefficient of Variation

Adding age into the model with years of contact lens wear increased the adjusted $\mathrm{R}^{2}$, but adding refractive error did not, therefore age was chosen to build the model of the coefficient of variation with years of contact lens wear. Finally, refractive error was added into the model with years of contact lens wear and age. Results showed that the adjusted $\mathrm{R}^{2}$ decreased, and the $\mathrm{p}$-value for refractive error was greater than 0.1 . This excluded refractive error from the final model. The factors in the best multivariate model of the coefficient of variation are years of contact lens wear and age.

\subsubsection{Evaluation of Interaction}

Age and years of contact lens wear have a biologically plausible interaction, therefore we checked for interaction. After adding interaction into the model, the adjusted $\mathrm{R}^{2}$ 
increased to .213 with a $\mathrm{p}$ value of .019 . Therefore the final model of coefficient of variation has age, years of contact lens wear, and the interaction term.

\subsubsection{Model Assumptions Check of the Final Model}

The final model, which includes age, years of contact lens wear, and the interaction term between age and years of contact lens wear, was checked for multiple regression model assumptions. Figures are shown in the appendix. No model assumptions were violated.

The final model for coefficient of variation is:

Coefficient of Variation $=24.3$

$$
\begin{aligned}
& +.72 * \text { Years of contact lens wear } \\
& +.18 * \text { Age } \\
& -.01 * \text { Interaction Age Years of contact lens wear }
\end{aligned}
$$

The adjusted $\mathrm{R}^{2}$ for this model is .213 , i.e., $21.3 \%$ of the variability of coefficient of variation can be explained by this model.

\subsection{Multiple Regression Model of the Percentage of Hexagonal Cells}

The mean percentage of hexagonal cells of all 149 subjects was $58.69 \% \pm 9.138$.

\subsubsection{Scatterplots}

Figures 3.11 to 3.15 are univariate scatterplots of the percentage of hexagonal cells versus all five independent variables. The percentage of hexagonal cell decreases with age, years of contact lens wear, and refractive error. In the scatterplots of the percentage of hexagonal cells versus age or race, no obvious tendency could be found. 


\subsubsection{Univariate Regression Analysis}

Table 3.12 is the summary of all univariate regression analyses for the percentage of hexagonal cells versus all five independent variables. Age, years of contact lens wear, and refractive error are all significantly correlated with the percentage of hexagonal cells. Race and gender, however, are not significant. The model with years of contact lens wear is the best univariate model, with the highest adjusted $\mathrm{R}^{2}$ of .182 and lowest MSE of 68.263.

\begin{tabular}{llllll}
\hline & $\beta$ & SE & $\mathrm{p}$ & MSE & Adjusted R2 \\
\hline Age & -.266 & .065 & $<.001$ & 75.56 & .095 \\
CL years & -.408 & .070 & $<.001$ & 68.26 & .183 \\
Rx & .933 & .237 & $<.001$ & 76.03 & .090 \\
Female & .237 & 1.532 & .877 & 84.07 & -.007 \\
Asian & 1.420 & 1.572 & .368 & 83.62 & -.001 \\
\hline
\end{tabular}

Table 3.12 Summary of Univariate Model for Percentage of Hexagonal Cells

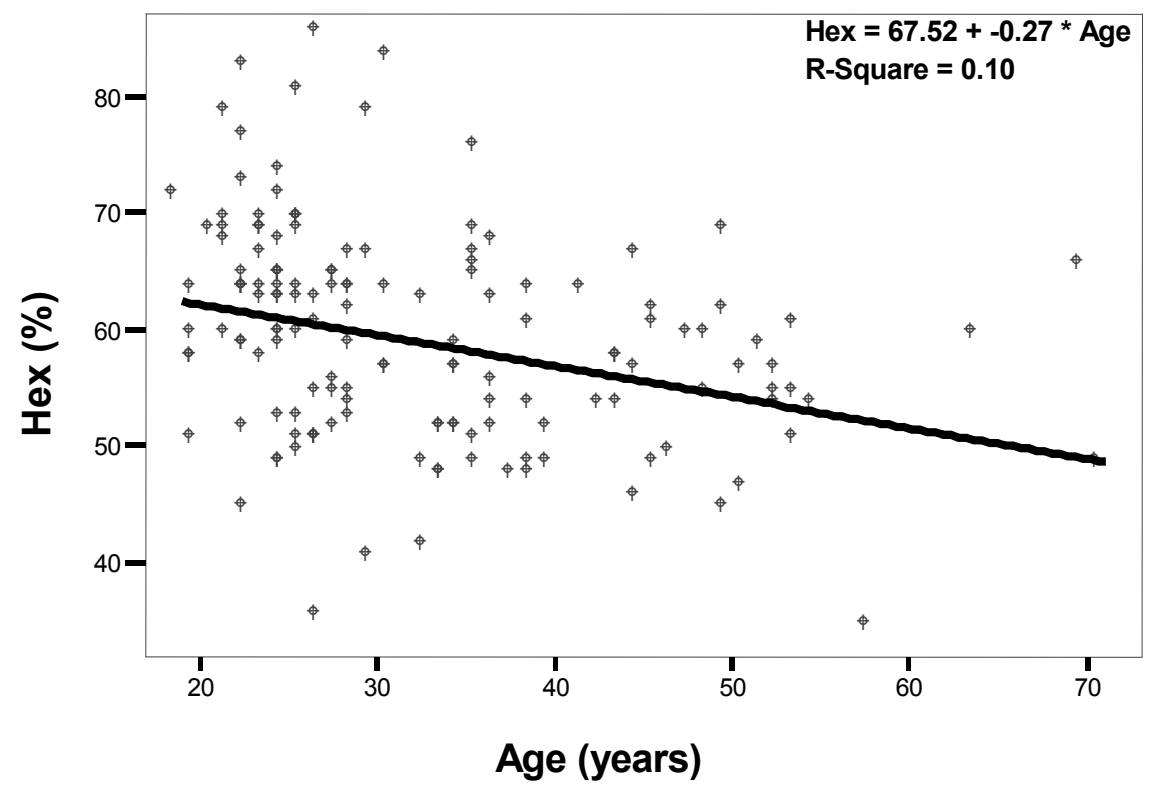

Figure 3.11 Scatterplot of Percentage of Hexagonal Cells versus Age 


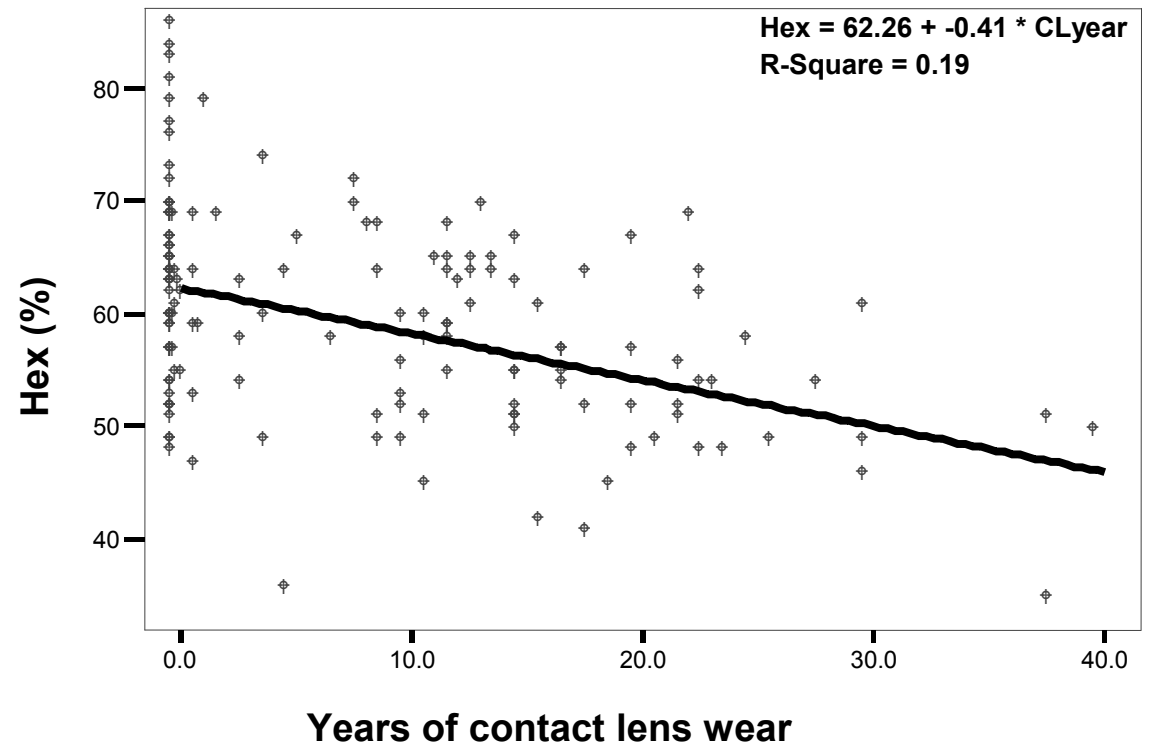

Figure 3.12 Scatterplot of Percentage of Hexagonal Cells versus Years of Contact Lens Wear

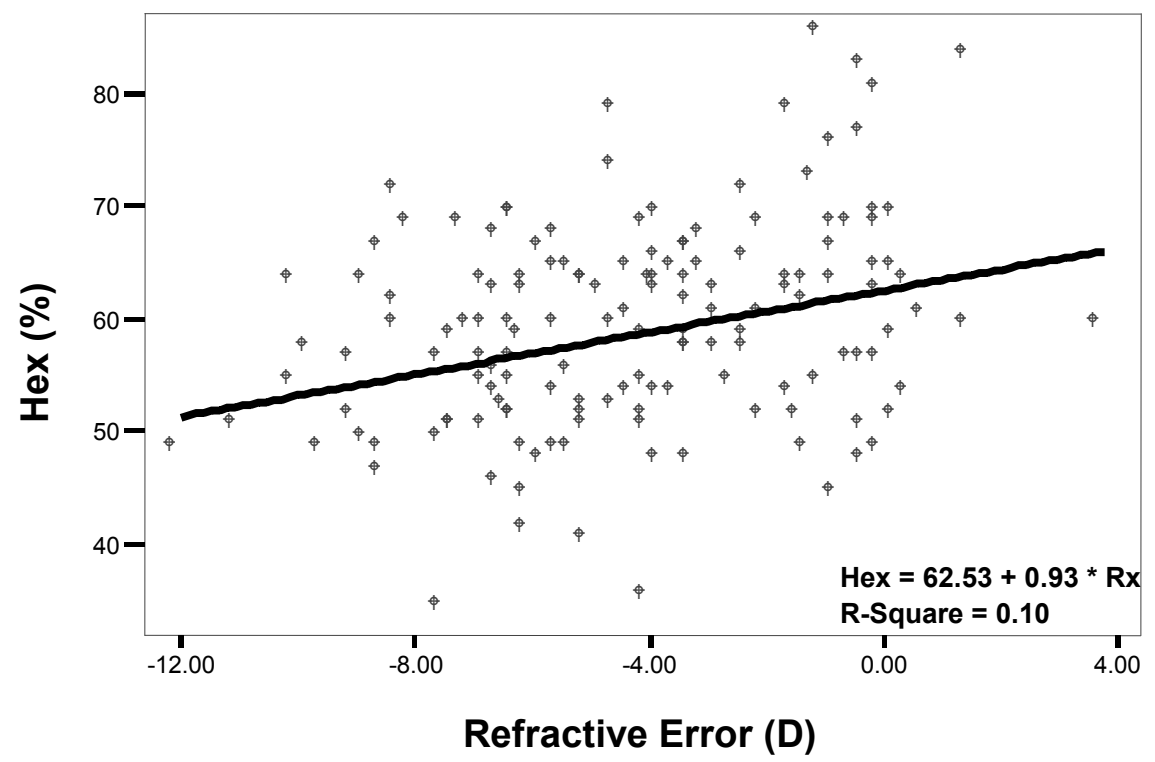

Figure 3.13 Scatterplot of Percentage of Hexagonal Cells versus Refractive Error 


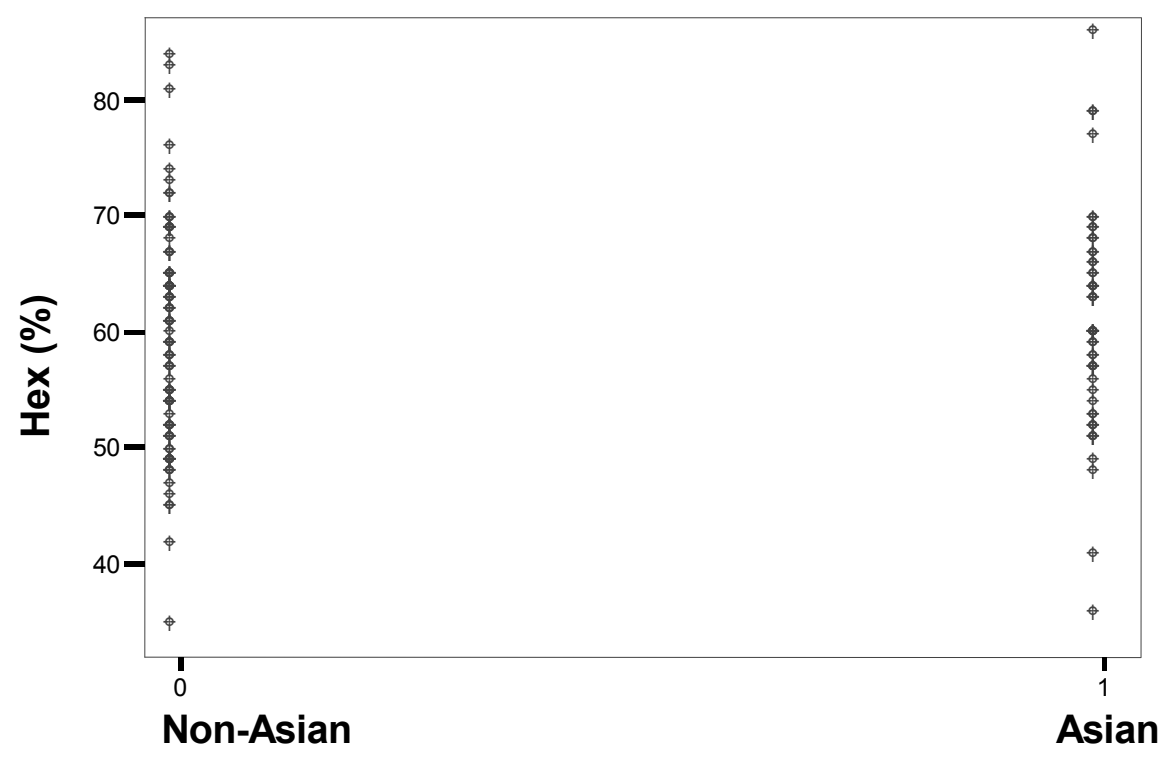

Figure 3.14 Scatterplot of Percentage of Hexagonal Cells versus Race

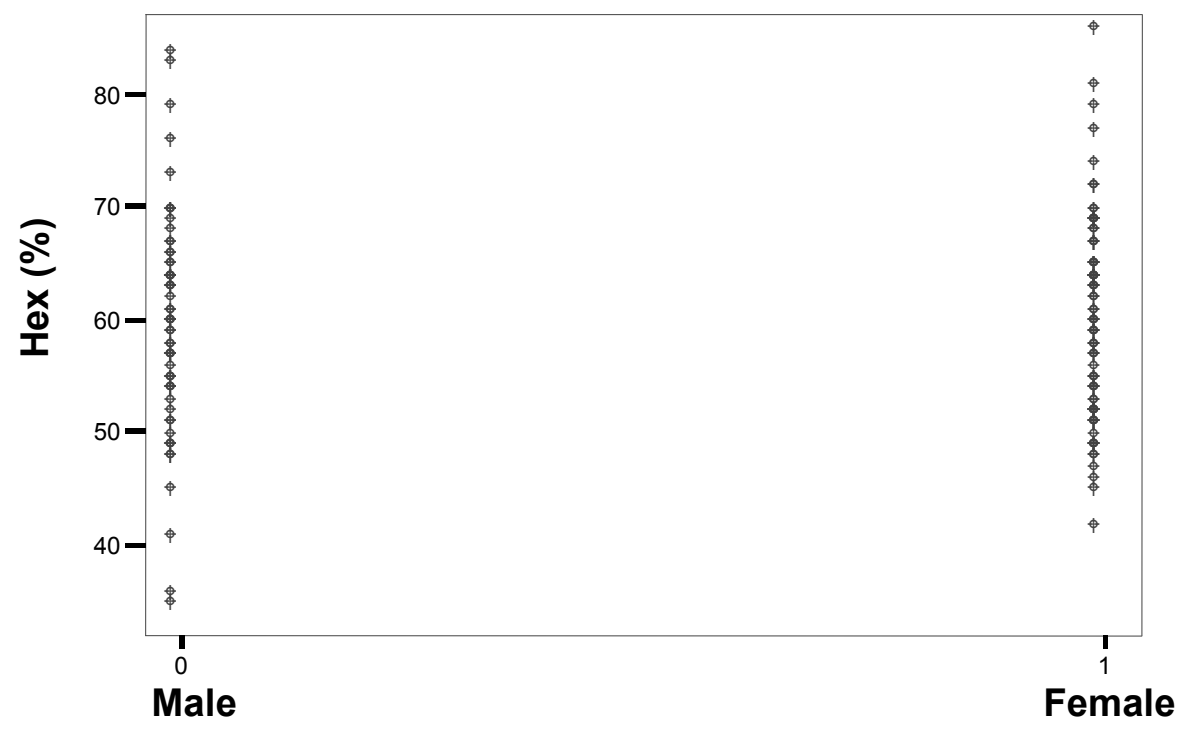

Figure 3.15 Scatterplot of Percentage of Hexagonal Cells versus Gender 


\subsubsection{Checks on Model Assumptions}

Figures shown in the appendix are checks of assumptions underlying linear model on all significant independent variables versus percentage of hexagonal cells Histogram and Normal probability plots check for normality assumption; the scatterplot of unstandardized residuals versus predicted values checks for linearity; scatterplot of studentized residuals versus predicted values checks for outliers, i.e., the assumption of equal variance.

Table 3.13 is the summary of model assumption checks. Results showed that normality, linearity, and equal variance assumptions were not violated in the univariate models of age, years of contact lens wear, and refractive error with the percentage of hexagonal cells. No further data transformation was necessary.

\begin{tabular}{llll}
\hline Variable & Normality & Linearity & Equal Variance \\
\hline Age & Yes & Yes & Yes \\
CL years & Yes & Yes & Yes \\
Rx & Yes & Yes & Yes \\
\hline
\end{tabular}

Table 3.13 Checks on Model Assumption for Percentage of Hexagonal Cells

\subsubsection{Multiple Regression Model Construction}

All significant factors in the univariate regression analysis were used to build the multiple regression model. Because years of contact lens wear had the highest adjusted $\mathrm{R}^{2}$ of .182 and lowest MSE, years of contact lens wear was included first. Then, two separate models were built by adding age and refractive error respectively. Results are shown in Table 3.14. 


\begin{tabular}{llllll}
\hline & $\beta$ & SE & $\mathrm{p}$ & MSE & Adjusted R2 \\
\hline Age & -.201 & .061 & .001 & 64.00 & .234 \\
Rx & .366 & .259 & .159 & 67.80 & .188 \\
\hline
\end{tabular}

Table 3.14 Summary on Model built with Years of Contact Lens Wear on Percentage of Hexagonal Cells

Adding age into the model with years of contact lens wear increased the adjusted $\mathrm{R}^{2}$. Therefore age was chosen to build the model of percentage of hexagonal cell with years of contact lens wear. Finally, refractive error was added into the model with years of contact lens wear and age. Results showed that the adjusted $\mathrm{R}^{2}$ increased from .234 to .244 , and the p-value for refractive error was less than 0.1 . Therefore refractive error was chosen to build the model of with years of contact lens wear and age in the model.

\subsubsection{Evaluation of Interaction}

Age and years of contact lens wear, age and refractive error, and refractive error and years of contact lens wear all have biologically plausible interactions, therefore we evaluated interactions. After adding interactions into the model respectively, the p-values were greater than 0.10 for all interaction terms $(p=.177$ for age and years of contact lens wear interaction; $p=.280$ for refractive error and years of contact lens wear interaction, $p=.688$ for age and refractive error interaction). These interactions were not significant in the multivariate model. Therefore the final model of percentage of hexagonal cell includes age, years of contact lens wear, and refractive error. 


\subsubsection{Model Assumptions Evaluation of the Final Model}

The final model, which includes age, years of contact lens wear, and refractive error, was evaluated for multiple regression model assumptions. Figures are shown in the appendix. No model assumptions were violated.

The final model for percentage of hexagonal cell is:

$\% \mathrm{Hex}=70$

$-0.29 *$ Years of contact lens wear

$-0.21 *$ Age

$+0.40 *$ Refractive error

The adjusted $\mathrm{R}^{2}$ for this model is .244 , i.e., $24.4 \%$ of the variability in the percentage of hexagonal cells can be explained by this model.

We performed a correlation analysis between endothelial cell density, the coefficient of variation, and the percentage of hexagonal cells. The results showed that a significant linear relationship exists between all three variables. The correlation between the coefficient of variation and the percentage of hexagonal cells $\left(r^{2}=0.54\right)$ was, however, much higher than that between endothelial cell density and either coefficient of variation $\left(r^{2}=0.10\right)$ or percentage of hexagonal cells $\left(r^{2}=0.07\right)$. 


\section{CHAPTER 4}

\section{DISCUSSION}

Using multiple regression analysis, we found that three aspects of corneal endothelial morphology, including endothelial cell density, the coefficient of variation, and the percentage of hexagonal cells, do not reflect same features of the cornea. Among the

factors we studied, including age, gender, race, years of contact lens wear, and refractive error, only age and race were found to be significantly related to corneal endothelial cell density. Asian people have higher corneal endothelial cell density than non- Asian.

The best model of corneal endothelial cell density wais:

$\mathrm{ECD}=3275-12.7 *$ Age $+(163.919$ if Asian $)$.

The results are consistent with previous studies of age as a single factor in cornea endothelial cell morphology change (Laing, Sandstrom et al. 1976; Hoffer and Kraff 1980; Cheng, Jacobs et al. 1985; Yee, Matsuda et al. 1985). Years of contact lens wear have been reported by some studies to have caused corneal endothelial cell density decrease (Setala, Vasara et al. 1998; Bourne, Holtan et al. 1999; Lee, Park et al. 2001), and years of contact lens wear was a significant factor in our univariate analysis. However, years of contact lens wear was not a significant factor in the multiple regression model of corneal endothelial cell density. The following factors may be responsible for the differences between studies: 
1. Research design and the statistical methods: Given that corneal endothelial morphology is related to multiple factors, multiple regression analysis is the most appropriate statistical methods method. Multiple regression analysis can control the confounding factors, can prioritize the significant factors in the final model, and can evaluate interactions between factors. Most previous studies had have control groups in their study (Eric 1985, Matsuda 1988, MacRae 1985, 1994, Setala 1998, Lee 2000); however, most studies only considered age as a confounding factor. Race was not mentioned in the research design of most studies. Diabetes, which could cause corneal endothelial morphology change and should be excluded, was not mentioned either. To the best of our knowledge, there are no studies that have evaluated interactions between these risk factors. In Holden's study on the effect of long-term contact lens wear on the cornea, he used one eye with contact lens wear as the treatment group and the other eye without contact lens wear as control group. Refractive error was not taken into consideration. In Holden's study, only the coefficient of variation increase was found and no endothelial cell density change was found (Holden 1985). Inoue et al. used multiple regression analysis and evaluated the effect of age, gender, axial length, and diabetes on corneal endothelial cell morphology change in patients before cataract surgery, and age was found to be the major risk factor that affects corneal endothelial morphology (Inoue, Tokuda et al. 2002). 
2. Number of subjects: Most previous studies had less than 50 subjects (Eric 1985, Matsuda 1988, MacRae 1985, 1994, Setala 1998, Bourne et al., 1999, Lee 2001). Very few studies had more than a hundred subjects (Setala, Vasara et al. 1998). We had 101 contact lens wearers in our study.

3. Type of contact lens: Earlier studies had most subjects wearing PMMA or RGP lenses. Later studies had more subjects who wore soft lenses, and very recent studies have more subjects wearing high oxygen transmission soft contact lenses. Even though we could not determine the exact type and design of the contact lens worn throughout their lives from most of our subjects, considering the general contact lens development and market situation, we believe most of our soft lens wearing subjects are currently wearing contact lenses with high oxygen transmission. Therefore we speculate that modern high oxygen transmission contact lenses could cause less change in corneal endothelial morphology than the older types of contact lenses. Ideally, we should also study the effect of the type of contact lens on corneal endothelial morphology, and the information about the exact type and design of contact lens should have been collected. However, because of the relative small sample size in the PMMA (2 subjects) and RGP (16 subjects) wearer groups, it is not appropriate to do a multiple regression analysis of them as separate groups. We also found it is impossible to get very detailed information about the exact brand or design of the contact lens from most of our subjects. Therefore years of contact lens wear was used without differentiating types or designs of contact lenses. 
4. Improvement in endothelial morphology after cessation of low gas-permeable contact lens wear. A retrospective study was performed by Odenthal et al. in 61 subjects who stopped wearing PMMA or HEMA contact lenses and switched to RGP lenses, high water content soft lenses, or spectacles. The study found that there was a significant decrease in the coefficient of variation from $37.5 \%$ to $35.7 \%$ and an increase in the percentage of hexagonal cells from $54.2 \%$ to $56.2 \%$ after 6.8 years of follow-up time. The yearly endothelial cell density decrease was around $0.5 \%$ (Odenthal, Gan et al. 2005). This is consistent with the $0.6 \%$ per year loss found by Bourne et al in normal subjects. Edmonds et al. measured corneal endothelial morphology on 9 subjects before and 1 year after changing from low Dk hydrogel lenses to high Dk hydrogel lenses. They found that there was an average of $-2.6 \pm 4.3 \%$ of change in the coefficient of variation and an average of $2.0 \pm 6.8 \%$ change in the percentage of hexagonal cells (Edmonds, Pemberton et al. 2004). This also showed that corneal endothelial cells have the potency to recover after the stress is removed or lessened. It has also been found that there was a decrease of coefficient of variation in the corneas of patients after LASIK surgery, and the change was speculated to be caused by the cessation of contact lens wear (Collins, Carr et al. 2001). Therefore, because the corneal endothelial morphology is reversible, having subjects with complicated contact lens wearing history in different studies may cause the differences between studies.

It is known that Asian people have a higher prevalence of myopia (Lin 1988, 1996, Lam 1990, 1991, Seet 2001). Therefore, it is more common for Asian people to undergo vision correction treatment, such as contact lens wear, refractive surgery or other surgery 
for vision correction. All of these treatments can cause changes in the corneal endothelial cell morphology. Interestingly, we found that Asian people had a higher corneal endothelial cell density. This high endothelial cell density reserve may help the corneas to resist the detrimental effect of surgeries when Asian people undergo vision correction treatment.

Our results showed that in the multiple regression model of coefficient of variation and percentage of hexagonal cell, years of contact lens wear was a significant factor in both models.

The best model of coefficient of variation was:

$\mathrm{CoV}=24.3+.719 * \mathrm{CL}$ years $+.178 *$ Age $-.011 *$ Interaction Age CL years.

The best model of the percentage of hexagonal cells was:

$\% \mathrm{Hex}=69.977-0.293 * \mathrm{CL}$ years- $0.209 * \mathrm{Age}+0.403 * \mathrm{Rx}$.

We also examined the standard coefficient (beta) in order to compare the contributions of all variables in each model. Using the standard coefficient (beta), the model of the coefficient of variation is: $\mathrm{CoV}=1.049 * \mathrm{CL}$ years $+.293 *$ Age $-.727 *$ Interaction Age CL years. Using the standard coefficient (beta), the model of the percentage of hexagonal cells is: $\% \mathrm{Hex}=-3.12 * \mathrm{CL}$ years- $0.251 * \mathrm{Age}+.143 * \mathrm{Rx}$. The standard coefficient (beta) of years of contact lens wear is higher than the standard coefficient (beta) of age in both models, so contact lens wear has a stronger association with both the coefficient of variation and the percentage of hexagonal cells than age. 
Changes in the coefficient of variation and the percentage of hexagonal cells are thought to be the early changes that precede a decrease in the endothelial cell density. Pleomorphism and polymegethism indicates that the cornea is under stress, and endothelial cell density decrease indicates that cell death has happened (Mac Rae, Matsuda et al. 1986). In diabetes mellitus, corneal endothelial cell density decreased 14.6 years after the pleomorphism and polymegethism were observed (Schultz, Matsuda et al. 1985). Lee et al. postulate that the sequence of the corneal endothelial cell changes on contact lens wearers is a change in endothelial hexagonality followed by a change in coefficient of variation, with the cell density decreasing last (Lee, Park et al. 2001). Based on the results of this study, that endothelial cell density represents more about the natural property of human eye, such as age and race. Endothelial cell density is not very sensitive in reflecting pathological change, especially at an early disease stage or in changes that have a long process such as contact lens wear. The coefficient of variation and the percentage of hexagonal cells, on the contrary, are early indicators of pathological change in the cornea.

As we have discussed previously, it has been shown that the coefficient of variation and the percentage of hexagonal cells increased after cessation of low oxygen transmissible contact lens wear. This finding also supports the idea that the coefficient of variation and the percentage of hexagonal cells are more sensitive than corneal endothelial density in reflecting pathological change or recovery process of the cornea endothelium. 
Another reason why the percentage of hexagonal cells decrease could not always be found concurrently with corneal endothelial cell density decrease may be attributed to the way that the percentage of hexagonal cell is calculated. The results of the percentage of hexagonal cells was calculated as:

$\%$ Hex $=$ Hex $/($ Hex + Non-Hex $)$

At the early stage of corneal endothelial change, before any cells die to cause the total number of corneal endothelial cell to decrease, i.e., before the corneal endothelial cell density shows any change, as the number of hexagonal cell decreases, the number of nonhexagonal cells increases but the total number of corneal endothelial cell is the same. This will cause a decrease in the numerator and the denominator in the formula; thus the percentage of hexagonal cell decreases. As the stress on the corneal endothelium worsens, some cells will die and disappear from the endothelium. At some point, the number of non-hexagonal cells in the formula decreases as does the number of hexagonal cells, so both the numerator and the denominator in the formula decrease. The result is that there is no change in the calculation result, per se, of the percentage of hexagonal cells.

This may also explain why only corneal endothelial cell density decreased in some studies of corneal endothelial morphology change after cataract surgery, but no change in the percentage of hexagonal cells was found. Because cataract surgery is a stronger and faster stress to the cornea endothelium than contact lens wear, any change in the 
percentage of hexagonal cells could not be captured in most of these studies. For the stress that quickly induces corneal endothelial change, such as cataract surgery or other intraocular surgery, corneal endothelial cell density may still be the best indicator for investigating corneal endothelial morphology change.

In the model of the factors associated with the coefficient of variation, there was an interaction between age and years of contact lens wear. Age is a confounding factor in studies of contact lens wear on corneal endothelial morphology change. To achieve a reliable result in such studies, age must be considered as a confounding factor in the research design, and possible interactions between age and other factors should be analyzed.

In the multiple regression model of the percentage of hexagonal cells, refractive error was significantly associated with the percentage of hexagonal cells. Adding refractive error into the model increased $\mathrm{R}^{2}$ and the $\mathrm{p}$-value was less than $0.1(\mathrm{p}=0.088)$. There have been few studies that assessed refractive error with the corneal endothelial morphology. Hoffer et al. found that corneal endothelial cell density was slightly higher (1.6\%) in myopes than in emmetropes (Hoffer and Kraff 1980). However, in their study, age was not controlled for when comparing the myopes and emmetropes in terms of corneal endothelial cell density. As discussed above, age was the factor most highly associated with corneal endothelial cell density in the current study. Without controlling for age, the results may not be reliable. Urban et al found that corneal endothelial cell density decreased in eyes with high myopia and that there was a significant correlation between 
average cell area and the degree of myopia in subjects from 13 to 18 years old (Urban, Bakunowicz-Lazarczyk et al. 2002). Chang et al studied 216 Asian subjects with a mean age of 22.2 years and found that corneal endothelial density was less in eyes with longer axial length (Chang, Tsai et al. 2001). To the best of our knowledge, no refractive error influence on the coefficient of variation and/or the percentage of hexagonal cells has been reported. Because we studied subjects with high, moderate, and low myopia, we evaluated the scatterplot of the percentage of hexagonal cells versus refractive error to see if the results were influenced high the myopia group alone. The scatterplot showed an even distribution across all refractive error levels. Therefore, in studies of contact lens wear on corneal endothelial morphology change, refractive error must be considered as a confounding factor in the research design. Failure to control for refractive error may lead to invalid results.

We have evaluated factors that are associated with corneal endothelial cell density, the coefficient of variation, and the percentage of hexagonal cells respectively. However, there are some unanswered questions and limitations in this study:

1. This study was limited to the central corneal endothelial morphology. We did not measure the paracentral and peripheral corneal endothelial morphology. Others found that there was a $5.8 \%$ increase in paracentral and a $9.6 \%$ increase in peripheral cornea endothelial cell density compared with the central corneal endothelium (Amann, Holley et al. 2003). Therefore, a more comprehensive study that includes central, paracentral, 
and peripheral cornea endothelial morphology could provide more information about corneal endothelial cell morphology.

2. The age distribution of subjects in this study. We did not achieve a very balanced distribution of subjects' age in our study. More than fifty percent of our subjects were people younger than 30 years old because of the ease of recruiting college age students. Only $11.4 \%$ of our subjects were older than 50 years. A sample with a more even age distribution may generate models with slightly different coefficients for age.

3. Contact lens wear history. The contact lens wear history was retrospectively collected based on subjects' memory. There might be cases where the subjects did not report their years of contact lens wear accurately, especially for subjects who had worn contact lenses for many years and have changed types of contact lenses.

4. The reason why refractive error was associated with corneal endothelial morphology. Myopic corneas may be more fragile and more susceptible to mechanical stress, therefore the development and progression of myopia could gradually influence the corneal endothelial cells. However, the exact mechanism by which myopia causes corneal endothelial morphology change is beyond the scope of this study. Further studies are needed. 


\section{CHAPTER 5}

\section{EVALUATING THE VALIDITY OF THE CONFOSCAN3 IN CORNEAL ENDOTHELIUM CELL MORPHOLOGY MEASUREMENT}

\subsection{Introduction}

The Konan Noncon Robo Pachy Model SP-9000LC specular microscope and KSS 300 software are the gold-standard methods for corneal endothelium morphology analysis. The Konan Noncon Robo Pachy Model SP-9000LC specular microscope is a non-contact instrument. No topical corneal anesthesia is needed. The precision of the Konan Noncon Robo Pachy in corneal endothelial morphology analysis is reported to be $2 \%$ for a study conducted at a single clinical site, with a single photographer, and a single reader. For a multicenter study, precision varies from $8 \%$ to $10 \%$ with a single reader (Edelhauser, personal communication). As a non-contact specular microscope, the Konan Noncon Robo specular microscope is easy to use; it is also patient friendly because no local anesthesia is needed. However, sometimes the resolution of the images taken by the Konan Noncon Robo Pachy Model SP-9000LC specular microscope are not good enough to be analyzed. This may make analyzing the corneal endothelial images difficult. 
The Confoscan3 uses a confocal biomicroscope to obtain images of the cornea. It produces images continuously of all layers of the cornea. Users may select the mode so that only endothelial images are taken. There is also an image analysis system in the Confoscan3 that allows automatic, semi-automatic (which uses correction tools to correct the mistakes made by automatic analysis), and manual endothelial image analysis. The Confoscan 3 is a corneal contact instrument that needs a drop of eye ointment placed on its probe. During the examination, the eye gel touches the cornea as the medium for the confocal microscope to take an image. The resolution of the image taken by the Confoscan 3 is superior to the endothelial image taken by a non-contacting specular microscope.

The specular microscope has been proved to be reliable and reproducible with appropriate calibration of the instrument (Benetz, Diaconu et al. 1999; Modis, Langenbucher et al. 2002; van Schaick, van Dooren et al. 2005). As a new instrument in corneal endothelial morphology analysis, the Confoscan3 was not widely evaluated in terms of its validity. In our study of the corneal endothelial cell morphology, we obtained images of the corneal endothelium of all subjects using both the Konan Noncon Robo specular microscope and the ConfoScan3 and evaluated the Nidek ConfoScan3 and its associated software that allows automated determination of corneal endothelial cell density, the coefficient of variation $(\mathrm{CoV})$, and the percentage of hexagonal cell (\%Hex). 


\subsection{Subjects and Methods}

Corneal endothelial images were obtained on 30 subjects with the Konan SP-9000 and the ConfoScan3. All subjects had no contact lens wearing history. The Konan images were analyzed with the KSS-300 center method, which required the operator to dot the center of the cells.

The Confoscan3 images were analyzed with automatic, semi-automatic, and manual methods. Automated software identified cell borders and scanned the image. The cell density, percentage of hexagonal cells $(\% \mathrm{Hex})$, and coefficient of variation $(\mathrm{CoV})$ were generated. The output of the automated analysis was edited by an operator (semiautomated method) who adjusted the cell borders and vertices. Cell density, the percentage of hexagonal cell $(\% \mathrm{Hex})$, and the coefficient of variation $(\mathrm{CoV})$ were the outcome variables for semi-automatic cell analysis. Confoscan manual cell analysis yielded cell density only. The protocol of Confoscan3 images analysis was:

- Select the one image with the most cells in focus or most clearly defined cells.

- Select the one image with the largest area of well-defined cells; cells can easily be manually dotted.

- The region of interest (ROI) should be $\geq .0400 \mathrm{~mm}^{2}$ to keep the area consistent 
The editing of the automatic analysis follows this protocol:

- Split or merge cells to get correct cell count

- Delete any cells with borders that extend outside the Region of interest (ROI)

- Switch to 'NO COLORS' and adjust cell borders to correct location by moving the vertices

- Switch to 'SIDES' to adjust cell vertices; Double click on border to add a vertex; Double click on vertex to delete it

- Go between original and analyzed image to double check the work

\subsection{Data Analysis}

The agreement between cell density, the percentage of hexagonal cell (\%Hex), and the coefficient of variation $(\mathrm{CoV})$ measurements and analysis methods were evaluated using Bland and Altman's difference versus mean method . The differences between pairs of measurements were calculated. The distribution of these differences was described by calculating the mean, the standard deviation of these differences, and the $95 \%$ limits of agreement (LoA). The LoA are calculated as the mean difference \pm 1.96 times the SD of the difference.

Evaluations were made on the following pairs of results:

ECD: Confoscan3 auto versus Konan, Confoscan3 semi-auto versus Konan, Confoscan manual versus Konan 
Percentage of hexagonal cells (\%Hex): Confoscan3 auto versus Konan, Confoscan3

semi-auto versus Konan

Coefficient of variation (CoV): Confoscan3 auto versus Konan, Confoscan3 semi-auto

versus Konan

\subsection{Results}

The agreement between the Confoscan 3 and Konan in corneal endothelial cell density, percentage of hexagonal cells $(\% \mathrm{Hex})$, and coefficient of variation $(\mathrm{CoV})$ measurement is shown in Table 5.1 to Table 5.3.

\begin{tabular}{l|ccc}
\hline & Mean & Standard Deviation & 95\% Limits of Agreement \\
\hline Automated & -46 & 158 & -356 to +263 \\
Semi-automated & -66 & 120 & -302 to +170 \\
\hline
\end{tabular}

TABLE 5.1. Agreement of Confoscan3 Estimates of Endothelial Cell Density with Konan KSS-300

\begin{tabular}{l|ccc}
\hline & Mean & Standard Deviation & 95\% Limits of Agreement \\
\hline Automated & +8.9 & 8.4 & -7.6 to +25.4 \\
Semi-automated & +0.2 & 4.4 & -8.4 to +8.8 \\
\hline
\end{tabular}

TABLE 5.2. Agreement of Confoscan3 Estimates of Percentage of Hexagonal Cells with Konan KSS-300

\begin{tabular}{l|ccc}
\hline & Mean & Standard Deviation & 95\% Limits of Agreement \\
\hline Automated & -9.2 & 8.9 & -26.6 to +8.3 \\
Semi-automated & +2.4 & 7.5 & -12.4 to +17.1 \\
\hline
\end{tabular}

TABLE 5.3. Agreement of Confoscan3 Estimates of Coefficient of Variation with Konan KSS-300 
For corneal endothelial cell density analysis, all methods gave similar mean values (around 2900 cells $/ \mathrm{mm}^{2}$ ). The agreement between the KSS-300 method and the semiautomated ConfoScan3 method $\left(95 \% \mathrm{LoA}=-302+170\right.$ cells $\left./ \mathrm{mm}^{2}\right)$ was slightly better than the agreement between the KSS-300 and the automated ConfoScan3 method (95\% LoA $=-356+263$ cells $/ \mathrm{mm}^{2}$ ). Figure 5.1 and Figure 5.2 showed the results.

For the coefficient of variation $(\mathrm{CoV})$ measurement, the automated Confoscan3 method also significantly overestimated the degree of coefficient of variation $(\mathrm{CoV})$ $(95 \% \mathrm{LoA}=-7.6$ to $+25.4 \% ; \mathrm{t}=5.8 ; \mathrm{p}<0.001) ;$ However, the semi-automated ConfoScan3 method agreed well with the KSS-300 method in coefficient of variation $(\mathrm{CoV})(95 \% \mathrm{LoA}=-8.4$ to $+8.8 \%)$. Figure 5.3 and Figure 5.4 showed the results.

For the percentage of hexagonal cells $(\% \mathrm{Hex})$ measurement, the automated Confoscan3 method significantly overestimated the degree of percentage of hexagonal cell (\%Hex) compared with the KSS-300 (95\% LoA $=-26.6$ to $+8.3 \% ; \mathrm{t}=5.7 ; \mathrm{p}<$ 0.001); however, the semi-automated ConfoScan3 method agreed well with the KSS-300 method in percentage of hexagonal cell $(\% \mathrm{Hex})(95 \% \mathrm{LoA}=-12.4$ to $+17.1 \%)$. Figure 5.5 and Figure 5.6 showed the results. 
ConfoScan3 (Automated) vs Konan

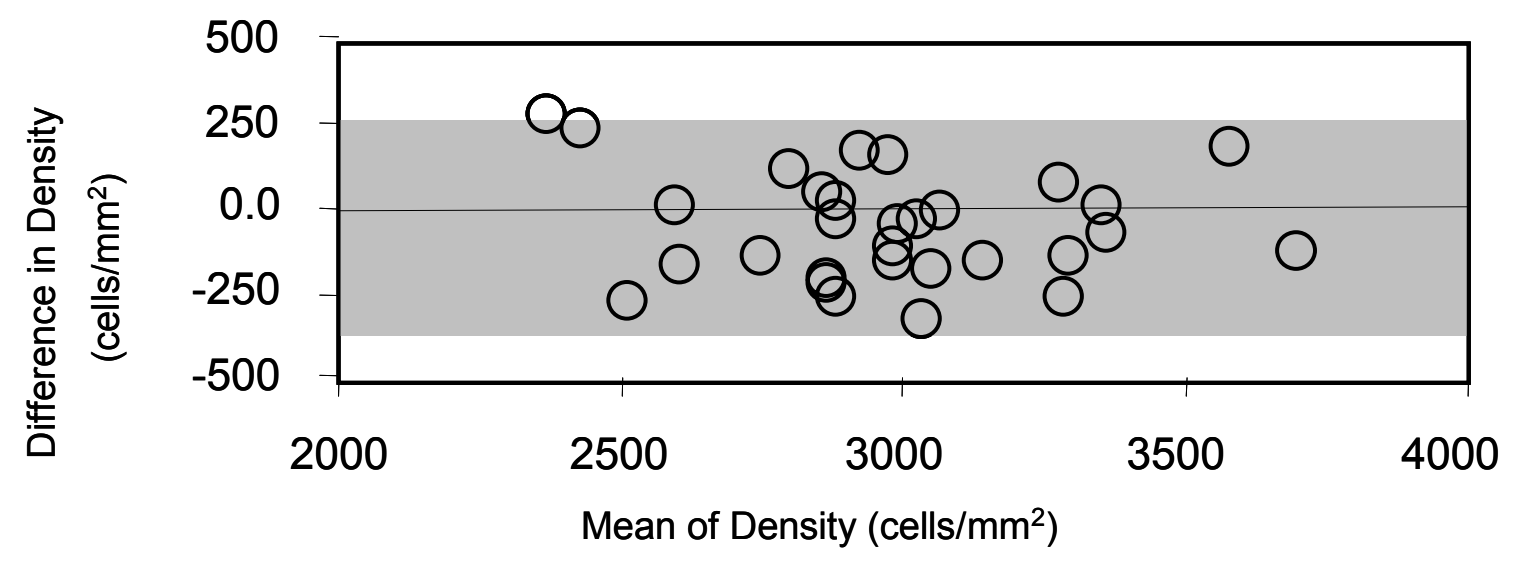

Figure 5.1 Agreement between Confoscan3 auto and Konan in ECD measurement

ConfoScan3 (Semi-automated) vs Konan

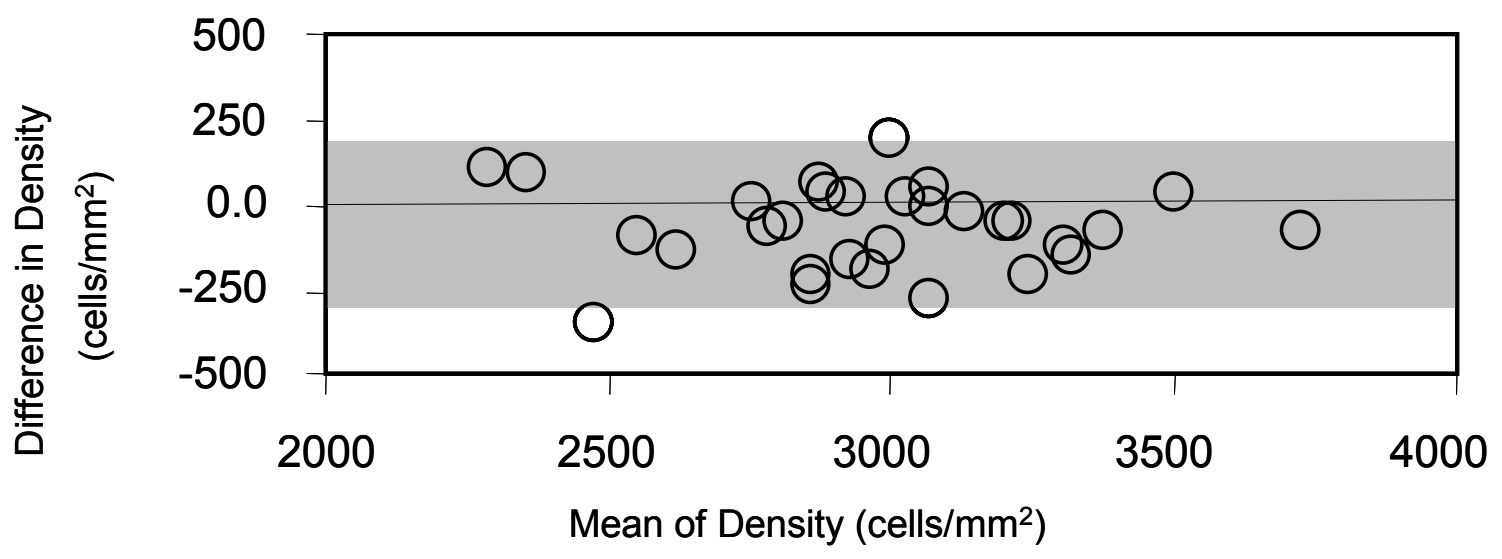

Figure 5.2 Agreement between Confoscan3 semi-auto and Konan in ECD measurement 
A. Confoscan (Automated) vs Konan

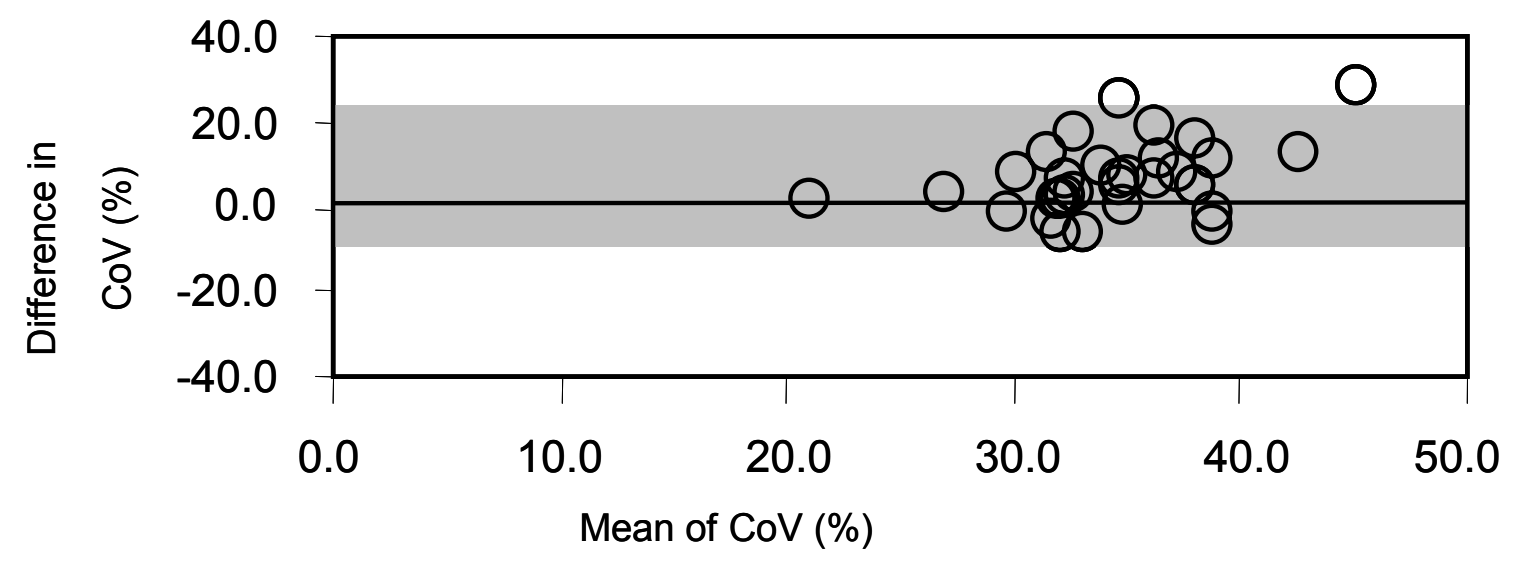

Figure 5.3 Agreement between Confoscan3 auto and Konan in Coefficient of Variation measurement

B. Confoscan (Semi-automated) vs Konan

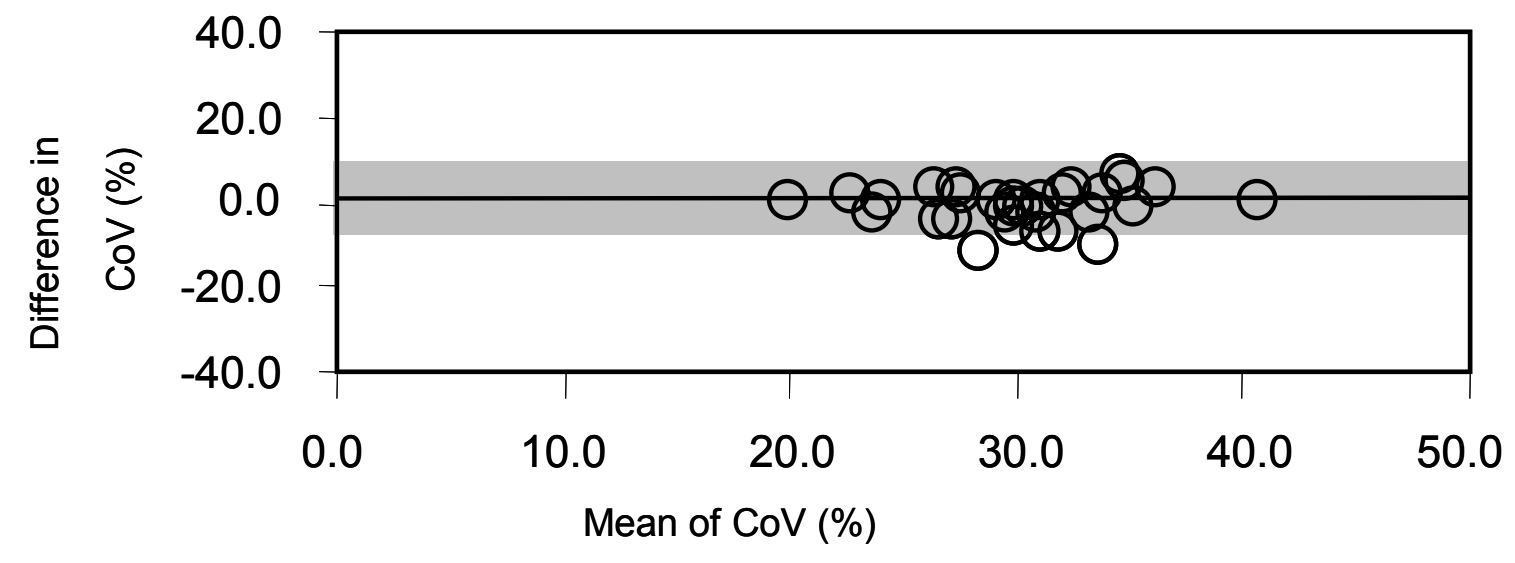

Figure 5.4 Agreement between Confoscan3 semi-auto and Konan in Coefficient of Variation measurement 


\section{A. Confoscan (Automated) vs Konan}

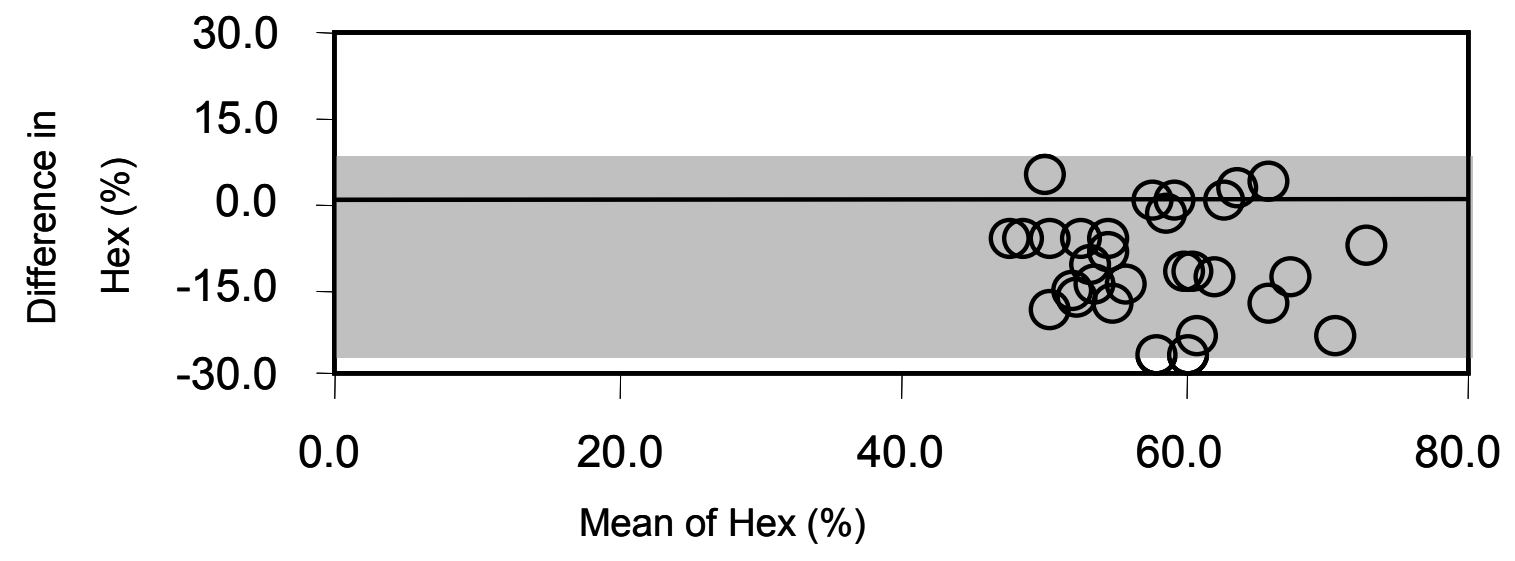

Figure 5.5 Agreement between Confoscan3 auto and Konan in \%Hex measurement

B. Confoscan (Semi-automated) vs Konan

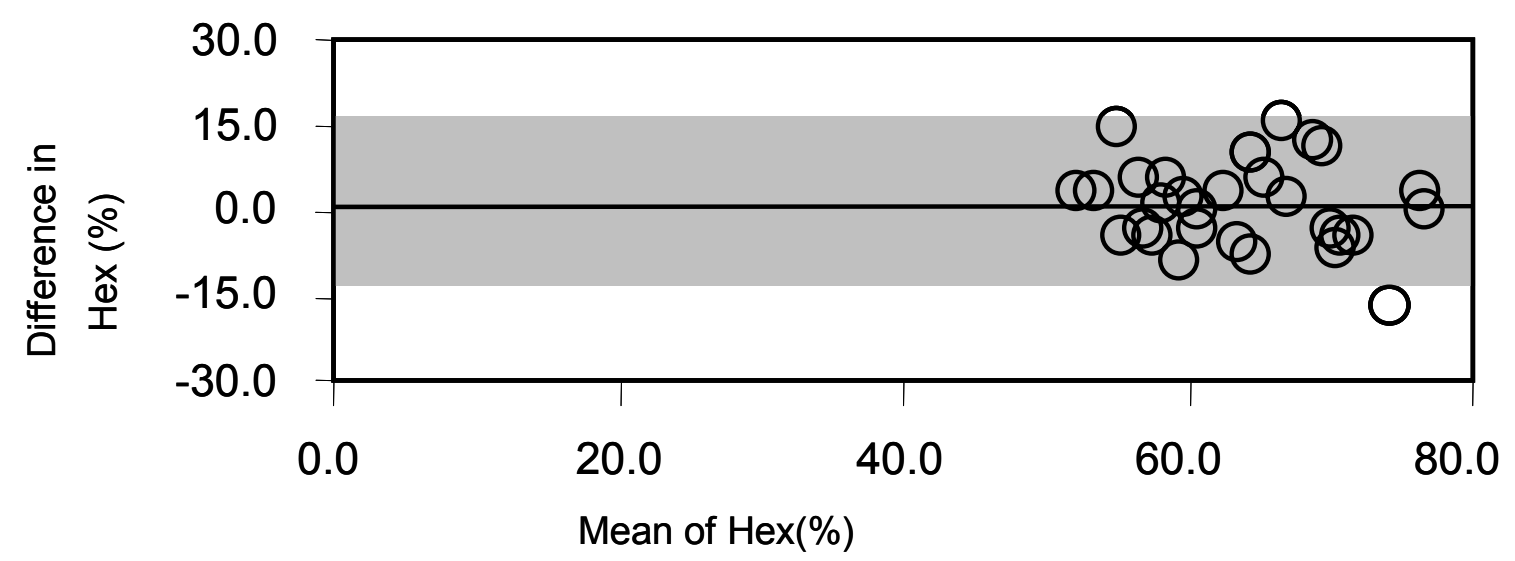

Figure 5.6 Agreement between Confoscan 3 semi-auto and Konan in \%Hex measurement 


\subsection{Discussion}

The Confoscan3 is a new instrument that can record sequences of images of the corneal endothelium. Compared with the Konan which is regarded as the gold standard in corneal endothelium image analysis, the Confoscan3 has the following advantages: it can capture higher resolution images than the Konan; it takes continuous images; it also has attached software that can do automatic cell analysis in a shorter time than the Konan.

However, the results of our study showed that the automatic method of the Confoscan3 is not valid for any of the three key aspects of corneal endothelial morphology analysis. It has a wider range of $95 \%$ LoA than the Konan in ECD measurement. It also overestimates the percentage of hexagonal cells $(\% \mathrm{Hex})$ and coefficient of variation $(\mathrm{CoV})$. The semiautomatic method improved the agreement between the Confoscan3 and Konan for all three aspects of corneal endothelial morphology analysis; therefore, semi-automatic method should be selected if a Confoscan3 is used to take corneal endothelial images. The Confoscan3 has some disadvantages compared to the Konan: the semi automatic method takes longer than Konan to analyze an image; as a contact instrument, the Confoscan3 requires local anesthesia; and the subjects' cooperation is crucial in taking images.

Therefore, in a study that has a larger sample size or involves multiple centers, the Konan is a better choice than the Confoscan3; however, the Confoscan 3 can capture high quality corneal endothelial images in patients with cornea gutatta, in patients with high 
degrees of corneal percentage of hexagonal cells (\%Hex) and/or a high coefficient of variation $(\mathrm{CoV})$, so it is still useful in some studies with a small sample size or involving a single center. 


\section{CHAPTER 6}

\section{CONCLUSION}

Using multiple regression analysis, we studied the factors affecting corneal endothelial morphology. We found that age and race were significantly associated with corneal endothelial cell density; age, years of contact lens wear, and the interaction term between age and years of contact lens wear were significantly associated with coefficient of variation; age, years of contact lens wear, and refractive error were significantly associated with percentage of hexagonal cells.

The results of this study proved that age, race, and refractive error are potential confounding factors in studies of corneal endothelial cell morphology change. Therefore, in studies of contact lens wear or other treatment or intervention on corneal endothelial morphology change, the above factors must be considered as a confounding factors in the research design. 


\section{BIBLIOGRAPHY}

American Academy of Ophthalmology. (1997). "Corneal endothelial photography. Three-year revision. " Ophthalmology 104(8): 1360-5.

Amann, J., G. P. Holley, et al. (2003). "Increased endothelial cell density in the paracentral and peripheral regions of the human cornea." Am J Ophthalmol 135(5): 58490.

Azar, R. G., M. J. Holdbrook, et al. (2001). "Two-year corneal endothelial cell assessment following INTACS implantation." J Refract Surg 17(5): 542-8.

Bahn, C. F., R. M. Glassman, et al. (1986). "Postnatal development of corneal endothelium." Invest Ophthalmol Vis Sci 27(1): 44-51.

Benetz, B. A., E. Diaconu, et al. (1999). "Comparison of corneal endothelial image analysis by Konan SP8000 noncontact and Bio-Optics Bambi systems." Cornea 18(1): $67-72$.

Bergmanson, J. P. (1992). "Histopathological analysis of corneal endothelial polymegethism." Cornea 11(2): 133-42.

Bourne, R. R., D. C. Minassian, et al. (2004). "Effect of cataract surgery on the corneal endothelium: modern phacoemulsification compared with extracapsular cataract surgery." Ophthalmology 111(4): 679-85.

Bourne, W. M., S. B. Holtan, et al. (1999). "Morphologic changes in corneal endothelial cells during 3 years of fluorocarbon contact lens wear." Cornea 18(1): 29-33.

Bourne, W. M. and H. E. Kaufman (1976). "Endothelial damage associated with intraocular lenses." Am J Ophthalmol 81(4): 482-5.

Bourne, W. M., L. R. Nelson, et al. (1994). "Continued endothelial cell loss ten years after lens implantation." Ophthalmology 101(6): 1014-22; discussion 1022-3.

Bourne, W. M., L. R. Nelson, et al. (1997). "Central corneal endothelial cell changes over a ten-year period." Invest Ophthalmol Vis Sci 38(3): 779-82. 
Carlson, K. H. and W. M. Bourne (1988). "Endothelial morphologic features and function after long-term extended wear of contact lenses." Arch Ophthalmol 106(12): 1677-9.

Carlson, K. H., W. M. Bourne, et al. (1988). "Effect of long-term contact lens wear on corneal endothelial cell morphology and function." Invest Ophthalmol Vis Sci 29(2): 185-93.

Carlson, K. H., W. M. Bourne, et al. (1988). "Variations in human corneal endothelial cell morphology and permeability to fluorescein with age." Exp Eye Res 47(1): 27-41.

Chang, S. W., I. L. Tsai, et al. (2001). "The cornea in young myopic adults." Br J Ophthalmol 85(8): 916-20.

Cheng, H., P. M. Jacobs, et al. (1985). "Precision of cell density estimates and endothelial cell loss with age." Arch Ophthalmol 103(10): 1478-81.

Cho, P. and S. W. Cheung (2000). "Central and peripheral corneal thickness measured with the TOPCON specular microscope SP-2000P." Curr Eye Res 21(4): 799-807.

Collins, M. J., J. D. Carr, et al. (2001). "Effects of laser in situ keratomileusis (LASIK) on the corneal endothelium 3 years postoperatively." Am J Ophthalmol 131(1): 1-6.

Doughty, M. J. (1998). "Prevalence of 'non-hexagonal' cells in the corneal endothelium of young Caucasian adults, and their inter-relationships." Ophthalmic Physiol Opt 18(5): 415-22.

Doughty, M. J., D. Fonn, et al. (1993). "Assessment of the reliability of calculations of the coefficient of variation for normal and polymegethous human corneal endothelium." Optom Vis Sci 70(9): 759-70.

Edelhauser, H. F., D. R. Sanders, et al. (2004). "Corneal endothelial assessment after ICL implantation." J Cataract Refract Surg 30(3): 576-83.

Edmonds, C., Pemberton, B et al. (2004) Endothelial morphology 1 year after refitting hydrogel lens wearers with Lotrafilcon A silicone hydrogel lenses. Paper presented to the American Academy of Optometry, December 2004, Tampa, Florida. Optom Vis Sci $81: 85$.

Gagnon, M. M., H. M. Boisjoly, et al. (1997). "Corneal endothelial cell density in glaucoma." Cornea 16(3): 314-8.

Grossniklaus, H. E., A. K. Hutchinson, et al. (1994). "Clinicopathologic features of surgically excised choroidal neovascular membranes." Ophthalmology 101(6): 1099-111. 
Hara, M., N. Morishige, et al. (2003). "Comparison of confocal biomicroscopy and noncontact specular microscopy for evaluation of the corneal endothelium." Cornea 22(6): 512-5.

Hoffer, K. J. and M. C. Kraff (1980). "Normal endothelial cell count range." Ophthalmology 87(9): 861-6.

Holden, B. A., D. F. Sweeney, et al. (1985). "Effects of long-term extended contact lens wear on the human cornea." Invest Ophthalmol Vis Sci 26(11): 1489-501.

Inoue, K., S. Kato, et al. (2002). "The corneal endothelium and thickness in type II diabetes mellitus." Jpn J Ophthalmol 46(1): 65-9.

Inoue, K., Y. Tokuda, et al. (2002). "Corneal endothelial cell morphology in patients undergoing cataract surgery." Cornea 21(4): 360-3.

Ishikawa, A. (2002). "Risk factors for reduced corneal endothelial cell density before cataract surgery." J Cataract Refract Surg 28(11): 1982-92.

Jones, S. S., R. G. Azar, et al. (1998). "Effects of laser in situ keratomileusis (LASIK) on the corneal endothelium." Am J Ophthalmol 125(4): 465-71.

Jung, S. E., K. Y. Seo, et al. (2002). "Expression of MUC1 on corneal endothelium of human." Cornea 21(7): 691-5.

Keoleian, G. M., J. M. Pach, et al. (1992). "Structural and functional studies of the corneal endothelium in diabetes mellitus." Am J Ophthalmol 113(1): 64-70.

Kim, E. K., D. H. Geroski, et al. (1992). "Corneal endothelial cytoskeletal changes in Factin with aging, diabetes, and after cytochalasin exposure." Am J Ophthalmol 114(3): 329-35.

Kim, T., A. L. Sorenson, et al. (2001). "Acute corneal endothelial changes after laser in situ keratomileusis." Cornea 20(6): 597-602.

Laing, R. A., M. Sandstrom, et al. (1976). "Morphological changes in corneal endothelial cells after penetrating keratoplasty." Am J Ophthalmol 82(3): 459-64.

Lee, J. S., W. S. Park, et al. (2001). "A comparative study of corneal endothelial changes induced by different durations of soft contact lens wear." Graefes Arch Clin Exp Ophthalmol 239(1): 1-4.

Lim, K. S. (2003). "Corneal endothelial cell damage from glaucoma drainage device materials." Cornea 22(4): 352-4. 
Lim, R., P. Mitchell, et al. (1999). "Refractive associations with cataract: the Blue Mountains Eye Study." Invest Ophthalmol Vis Sci 40(12): 3021-6.

Lundberg, B., M. Jonsson, et al. (2005). "Postoperative corneal swelling correlates strongly to corneal endothelial cell loss after phacoemulsification cataract surgery." Am J Ophthalmol 139(6): 1035-41.

Mac Rae, S. M., M. Matsuda, et al. (1986). "The effects of hard and soft contact lenses on the corneal endothelium." Am J Ophthalmol 102(1): 50-7.

MacRae, S. M., M. Matsuda, et al. (1994). "The long-term effects of polymethylmethacrylate contact lens wear on the corneal endothelium." Ophthalmology 101(2): 365-70.

MacRae, S. M., M. Matsuda, et al. (1986). "The effects of hard and soft contact lenses on the corneal endothelium." Am J Ophthalmol 102(1): 50-7.

MacRae, S. M., M. Matsuda, et al. (1985). "The effect of long-term hard contact lens wear on the corneal endothelium." Clao J 11(4): 322-6.

Mandell, R. B., K. A. Polse, et al. (1989). "Corneal hydration control in Fuchs' dystrophy." Invest Ophthalmol Vis Sci 30(5): 845-52.

Marshall, J. and C. F. Grindle (1978). "Fine structure of the cornea and its development." Trans Ophthalmol Soc U K 98(3): 320-8.

Matsuda, M., N. Ohguro, et al. (1990). "Relationship of corneal endothelial morphology to diabetic retinopathy, duration of diabetes and glycemic control." Jpn J Ophthalmol 34(1): 53-6.

Matsuda, M., T. Suda, et al. (1984). "Serial alterations in endothelial cell shape and pattern after intraocular surgery." Am J Ophthalmol 98(3): 313-9.

Menezo, J. L., A. L. Cisneros, et al. (1998). "Endothelial study of iris-claw phakic lens: four year follow-up." J Cataract Refract Surg 24(8): 1039-49.

Milla, E., C. Verges, et al. (2005). "Corneal endothelium evaluation after phacoemulsification with continuous anterior chamber infusion." Cornea 24(3): 278-82.

Modis, L., Jr., A. Langenbucher, et al. (2002). "Corneal endothelial cell density and pachymetry measured by contact and noncontact specular microscopy." J Cataract Refract Surg 28(10): 1763-9.

Muller, A., M. J. Doughty, et al. (2000). "Reassessment of the corneal endothelial cell organisation in children." Br J Ophthalmol 84(7): 692-6. 
Nichols, J. J., G. M. Kosunick, et al. (2003). "Reliability of corneal thickness and endothelial cell density measures." J Refract Surg 19(3): 344-52.

Nucci, P., R. Brancato, et al. (1990). "Normal endothelial cell density range in childhood." Arch Ophthalmol 108(2): 247-8.

O'Brien, P. D., P. Fitzpatrick, et al. (2004). "Risk factors for endothelial cell loss after phacoemulsification surgery by a junior resident." J Cataract Refract Surg 30(4): 839-43.

O'Neal, M. R. and K. A. Polse (1985). "In vivo assessment of mechanisms controlling corneal hydration." Invest Ophthalmol Vis Sci 26(6): 849-56.

Odenthal, M. T., I. M. Gan, et al. (2005). "Long-term changes in corneal endothelial morphology after discontinuation of low gas-permeable contact lens wear." Cornea 24(1): $32-8$.

Ogawa, A. and M. Tanaka (1988). "The relationship between refractive errors and retinal detachment--analysis of 1,166 retinal detachment cases." Jpn J Ophthalmol 32(3): 310-5.

Ohguro, N., M. Matsuda, et al. (1999). "Corneal endothelial changes in patients with chronic renal failure." Am J Ophthalmol 128(2): 234-6.

Olsen, T. (1979). "Variations in endothelial morphology of normal corneas and after cataract extraction. A specular microscopic study." Acta Ophthalmol (Copenh) 57(6): 1014-9.

Perez-Santonja, J. J., H. F. Sakla, et al. (1997). "Corneal endothelial changes after laser in situ keratomileusis." J Cataract Refract Surg 23(2): 177-83.

Polse, K. A., R. Brand, et al. (1989). "Age differences in corneal hydration control." Invest Ophthalmol Vis Sci 30(3): 392-9.

Rao, G. N., J. V. Aquavella, et al. (1984). "Pseudophakic bullous keratopathy. Relationship to preoperative corneal endothelial status." Ophthalmology 91(10): 1135-40.

Saini, J. S. and S. Mittal (1996). "In vivo assessment of corneal endothelial function in diabetes mellitus." Arch Ophthalmol 114(6): 649-53.

Saini, J. S. and S. Mittal (1996). "In vivo evaluation of corneal endothelial function following cataract surgery." Ophthalmic Surg Lasers 27(12): 1000-4.

Saini, J. S., S. Mittal, et al. (1998). "Evaluation of endothelial function in postkeratoplasty eyes." Ophthalmic Surg Lasers 29(4): 300-4. 
Sakai, R., T. Kinouchi, et al. (2002). "Construction of human corneal endothelial cDNA library and identification of novel active genes." Invest Ophthalmol Vis Sci 43(6): 174956.

Schultz, R. O., M. Matsuda, et al. (1984). "Corneal endothelial changes in type I and type II diabetes mellitus." Am J Ophthalmol 98(4): 401-10.

Schultz, R. O., M. Matsuda, et al. (1985). "Long-term survival of cryopreserved corneal endothelium." Ophthalmology 92(12): 1663-7.

Setala, K., K. Vasara, et al. (1998). "Effects of long-term contact lens wear on the corneal endothelium." Acta Ophthalmol Scand 76(3): 299-303.

Sihota, R., N. C. Lakshmaiah, et al. (2003). "Corneal endothelial status in the subtypes of primary angle closure glaucoma." Clin Experiment Ophthalmol 31(6): 492-5.

Smith, C. A., J. M. Khoury, et al. (2000). "Unexpected corneal endothelial cell decompensation after intraocular surgery with instruments sterilized by plasma gas." Ophthalmology 107(8): 1561-6; discussion 1567.

Speedwell, L., P. Novakovic, et al. (1988). "The infant corneal endothelium." Arch Ophthalmol 106(6): 771-5.

Sperduto, R. D., D. Seigel, et al. (1983). "Prevalence of myopia in the United States." Arch Ophthalmol 101(3): 405-7.

Stocker, E. G. and J. P. Schoessler (1985). "Corneal endothelial polymegathism induced by PMMA contact lens wear." Invest Ophthalmol Vis Sci 26(6): 857-63.

Stulting, R. D., K. P. Thompson, et al. (1996). "The effect of photorefractive keratectomy on the corneal endothelium." Ophthalmology 103(9): 1357-65.

Urban, B., A. Bakunowicz-Lazarczyk, et al. (2002). "[Corneal endothelium in children and adolescents with myopia]." Klin Oczna 104(5-6): 381-3.

van Schaick, W., B. T. van Dooren, et al. (2005). "Validity of endothelial cell analysis methods and recommendations for calibration in Topcon SP-2000P specular microscopy." Cornea 24(5): 538-44.

Vannas, A., K. Setala, et al. (1977). "Endothelial cells in capsular glaucoma." Acta Ophthalmol (Copenh) 55(6): 951-8.

Ventura, A. C., R. Walti, et al. (2001). "Corneal thickness and endothelial density before and after cataract surgery." Br J Ophthalmol 85(1): 18-20. 
Vongphanit, J., P. Mitchell, et al. (2002). "Prevalence and progression of myopic retinopathy in an older population." Ophthalmology 109(4): 704-11.

Waring, G. O., 3rd, W. M. Bourne, et al. (1982). "The corneal endothelium. Normal and pathologic structure and function." Ophthalmology 89(6): 531-90.

Wiffen, S. J., D. O. Hodge, et al. (2000). "The effect of contact lens wear on the central and peripheral corneal endothelium." Cornea 19(1): 47-51.

Wirbelauer, C., G. Wollensak, et al. (2005). "Influence of cataract surgery on corneal endothelial cell density estimation." Cornea 24(2): 135-40.

Yee, R. W., M. Matsuda, et al. (1985). "Changes in the normal corneal endothelial cellular pattern as a function of age." Curr Eye Res 4(6): 671-8.

Younan, C., P. Mitchell, et al. (2002). "Myopia and incident cataract and cataract surgery: the blue mountains eye study." Invest Ophthalmol Vis Sci 43(12): 3625-32. 